Check for updates

Cite this: RSC Adv., 2019, 9, 25094

\title{
The role of hollow magnetic nanoparticles in drug delivery $\uparrow$
}

\author{
Ghodsi Mohammadi Ziarani, (DD *a Masoumeh Malmir, ${ }^{a}$ Negar Lashgari (D) ${ }^{a}$ \\ and Alireza Badiei ${ }^{b}$
}

The increasing number of scientific publications focusing on nanomaterials in the biomedical field indicates growing interest from the broader scientific community. Nanomedicine is a modern science, and research continues into the application of nanoscale materials for the therapy and diagnosis of damaged tissues. In this regard, substantial progress has been made in the synthesis of magnetic materials with desired sizes, morphologies, chemical compositions, and surface chemistry. Among these, magnetic iron oxide nanoparticles have demonstrated great promise as unique carriers in the delivery of chemical drugs due to their combinations of hollow structures. Importantly, due to the combination of the ability to respond to an external magnetic field and the rich possibilities of their coatings, magnetic materials are universal tools for the magnetic separation of small molecules, biomolecules, and cells. This review provides an overview of the synthesis and biological applications of hollow magnetic nanoparticles in drug delivery systems.

Received 2nd March 2019

Accepted 16th July 2019

DOI: $10.1039 / c 9 r a 01589 b$

rsc.li/rsc-advances the use of well-established templates, including hard templates, soft templates, and sacrificial templates. ${ }^{30-32} \mathrm{On}$ the other hand, magnetic hollow nanostructures can find various biomedical applications, including simultaneous diagnosis and therapy, because the large pore volumes inside the hollow nanostructures can be used to incorporate various drugs and bio-molecules and release them in a controlled manner. ${ }^{33}$ Additionally, the surfaces of the magnetic hollow nanostructures can be readily functionalized with targeting agents. ${ }^{34}$ Subsequent to our previous publications, ${ }^{35-38}$ herein, we wish to review the roles of various pure and modified hollow magnetic nanoparticles in drug delivery processes. Generally, we have classified the uses of HMNPs into three main concepts: preparation, functionalization and the role of HMNPs in drug delivery systems.

\section{Preparation and surface analysis of HMNPs}

\subsection{Preparation of HMNPs}

Magnetic nanoparticles with unique properties can be used as catalyst supports in organic transformations. Importantly, many attempts have been made to control the size and morphology of magnetic materials via changing reaction parameters such as temperature, time and concentration of reactants to manipulate their magnetic and surface properties. Magnetic nanoparticles can be divided into four categories: $^{39}$

- Metals (Fe, Co, Ni) 
- Metal oxides (FeO, $\mathrm{Fe}_{2} \mathrm{O}_{3}, \mathrm{Fe}_{3} \mathrm{O}_{4}$ )

- Alloys (FePt, FePd)

- Ferrites $\left(\mathrm{CoFe}_{2} \mathrm{O}_{4}, \mathrm{CuFe}_{2} \mathrm{O}_{4}\right)$

Among these categories, metal oxides with hollow structures have attracted much attention because of their simple preparation approach, strong magnetic properties and the sizes, shapes and low densities of the materials. Most of these compounds have been used as catalysts in organic transformations and photocatalysis. ${ }^{\mathbf{4 0}}$

Recently, Si and co-workers carefully reviewed the synthesis and applications of hollow micro and nanostructures. ${ }^{41}$ Several synthesis approaches for the fabrication of hollow magnetic nanoparticles, including templatemediated and reaction approaches, have been established. Meanwhile, template-free approaches were established to prepare hollow nano/microspheres, including Ostwald ripening, ${ }^{25}$ the Kirkendall effect (shell-breaking) ${ }^{27}$ and surface-protecting etching. ${ }^{30}$ Currently, various nanomagnetic hollow structures are produced via the Ostwald ripening approach. Additionally, pure nanomagnetic $\mathrm{Fe}_{2} \mathrm{O}_{3}$ hollow spheres can be prepared, according to experimental results by Elhampour and coworkers. ${ }^{5}$ Based on Fig. $1 \mathrm{~A}$ and $\mathrm{B}$, the nanomagnetic $\mathrm{Fe}_{2} \mathrm{O}_{3}$ particles are spherical, with an average diameter of $400 \mathrm{~nm}$; also, the hollow morphology of the nanomagnetic $\mathrm{Fe}_{2} \mathrm{O}_{3}$ particles is clearly revealed (Fig. 1). ${ }^{5}$

\subsection{Functionalization of HMNPs}

A wide range of stabilizing or coating materials, including organic (polymers and surfactants) ${ }^{\mathbf{4 2}}$ and inorganic (silica and carbon materials), ${ }^{43}$ have been used as some of the most powerful tools to strengthen the chemical stability of hollow magnetic nanoparticles. For example, various amphiphilic polymers, such as polystyrene-polyacrylic acid block copolymer (PS-PAA), tetradecylphosphonate and polyethylene glycol-2tetradecyl ether, have been successfully used to transfer hydrophobic magnetic nanoparticles from organic solvents to aqueous solution. ${ }^{\mathbf{4 4 , 4 5}}$ Meanwhile, various commercially available amphiphilic polymers provide different functional groups, including carboxylic acid, thiol, amine, carbonyl, and biotin, for immobilization of various biological moieties, such as peptides, proteins, and oligonucleotides. Moreover, the chemical

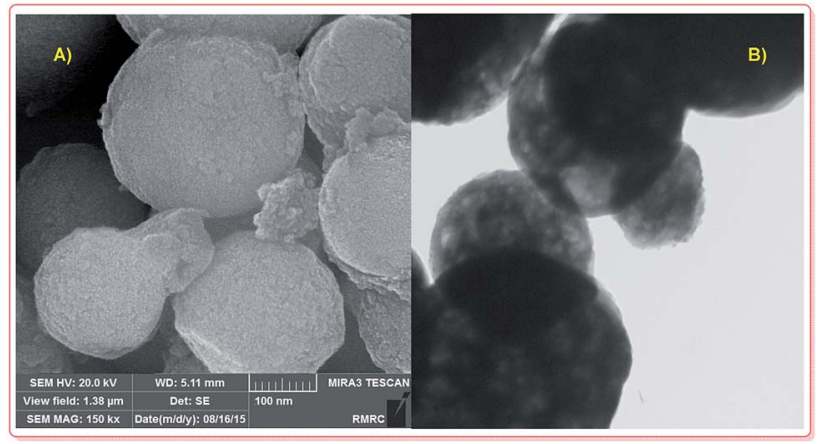

Fig. 1 FE-SEM (A) and TEM (B) analysis of $\mathrm{Fe}_{2} \mathrm{O}_{3}$ hollow spheres. ${ }^{5}$ properties of the coating material can be effective for the surface functionalization of magnetic nanoparticles.

\section{The roles of pure and modified HMNPs in the adsorption and release of drugs}

\subsection{Natural drugs (herbal medicines)}

3.1.1. Rhodamine B (RhB). Rhodamines, which include $B$ and 6G, are used extensively as chemical compounds and dyes in biotechnology applications such as flow cytometry, ${ }^{46}$ fluorescence microscopy, and fluorescence correlation spectroscopy. ${ }^{47}$

Recently, Chen and co-workers demonstrated the preparation of $\gamma-\mathrm{Fe}_{2} \mathrm{O}_{3}$ silica nanotubes $\left(\gamma-\mathrm{Fe}_{2} \mathrm{O}_{3} @ \mathrm{SiO}_{2}\right.$ tubes $)$, which were used as a carrier in a controlled RhB delivery system.

The total RhB capacity in the as-prepared tubes was $9.25 \mathrm{mg}$ per $g$ of carrier because of the large open ends from the pore diameter distribution in the magnetic nanotubes. In the UV-Vis spectrum of the tubes in aqueous media, the broad absorption band around $553 \mathrm{~nm}$ is characteristic of RhB; thus, its intensity enables estimation of the RhB concentration in the solution. Thus, in the first $5 \mathrm{~h}$, nearly $50 \%$ of the RhB was released from the carrier; then, about $80 \%$ of the loaded $\mathrm{RhB}$ was released within $9 \mathrm{~h}$ (Scheme 1). ${ }^{48}$

3.1.2. Rhodamine 6G (R6G). Recently, to investigate the functions of solubility parameters in drug delivery properties, PAA-coated hollow $\mathrm{Fe}_{3} \mathrm{O}_{4}$ nanoparticles were successfully synthesized by $\mathrm{He}$ et al. According to their results, the coating amount of PAA onto the surface of $\mathrm{Fe}_{3} \mathrm{O}_{4}$ (measured by TGA) was about $40 \%(\mathrm{w} / \mathrm{w})$. The efficiency of Rhodamine $6 \mathrm{G}$ (R6G) loading and the drug release of these $\mathrm{Fe}_{3} \mathrm{O}_{4} / \mathrm{PAA}$ nanocarriers were considered.

The R6G loading capacity in $\mathrm{Fe}_{3} \mathrm{O}_{4} / \mathrm{PAA}$ was $325.7 \mathrm{mg}$ per $\mathrm{mL}$ of carrier. The best drug release rate of $93.0 \%$ was achieved in $\mathrm{pH} 7.4$ PBS solution after $14 \mathrm{~h}$. The release efficiency was $86.5 \%$ in acidic conditions. Moreover, the solubility parameter can

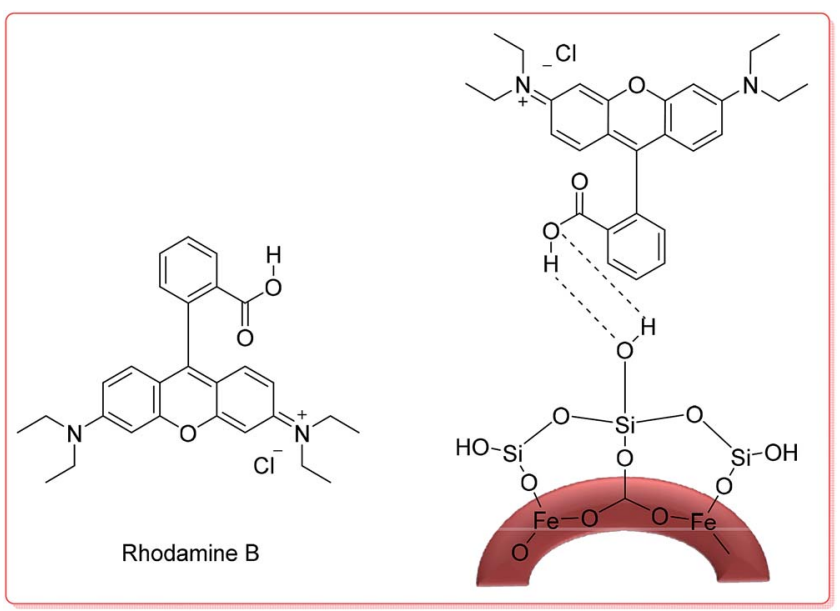

Scheme 1 The structures of $\mathrm{RhB}$ and $\mathrm{RhB}-\gamma-\mathrm{Fe}_{2} \mathrm{O}_{3}\left(\mathrm{ASiO}_{2} \cdot{ }^{48}\right.$ 
influence the swelling properties of PAA and the binding forces between PAA and R6G. ${ }^{49}$

\subsection{Nonsteroidal anti-inflammatory drugs (NSAIDs)}

\subsubsection{Ibuprofen (IBU)}

3.2.1.1. Metal oxides. Lu et al. synthesized hollow-coredouble-shell magnetic iron oxide/silica/calcium silicate nanocomposites (MSCN) which were used as-prepared for ibuprofen (IBU) delivery.

The maximum loading of IBU-MSCN was $75 \mathrm{mg}$ drug per $\mathrm{g}$. Moreover, the IBU release of IBU-MSCN in phosphate buffer saline (PBS) was rapid in the first $5 \mathrm{~h}$ at $37^{\circ} \mathrm{C}$; the drug release was complete at a release time of $60 \mathrm{~h}$ (Scheme 2). ${ }^{\mathbf{5 0}}$

In another study, to investigate HMNPs as carriers for IBU delivery, $\alpha-\mathrm{Fe}_{2} \mathrm{O}_{3}$ and $\mathrm{Fe}_{3} \mathrm{O}_{4}$ hollow spheres were prepared by Sasidharan and co-workers. The drug storage capacities of the two nanoparticles were 0.26 to $0.29 \mathrm{~g}$ IBU per $\mathrm{g}$ of carrier; also, about $96 \%$ of the IBU was released into PBS solution at $\mathrm{pH} 7.3$ overnight. ${ }^{51}$

Cao et al. synthesized PEG-coated $\mathrm{Fe}_{3} \mathrm{O}_{4}$ and PEG-coated $\gamma$ $\mathrm{Fe}_{2} \mathrm{O}_{3}$ hollow spheres (Fig. S1a and $\mathrm{b} \dagger$ ) from ferrous alkoxide by two different methods. Then, they used the PEG-coated $\gamma-\mathrm{Fe}_{2} \mathrm{O}_{3}$ hollow spheres as a carrier to deliver IBU at $\mathrm{pH} 7.4$ under shaking at a constant rate in simulated body fluid (SBF) at $37^{\circ} \mathrm{C}$. Additionally, IBU was maintained in these hierarchically nanostructured hollow spheres, with uptake amounts of 237 and $297 \mathrm{mg} \mathrm{g}^{-1}$ for PEG-coated $\gamma-\mathrm{Fe}_{2} \mathrm{O}_{3}$ and PEG-coated $\mathrm{Fe}_{3} \mathrm{O}_{4}$, respectively; the drug molecules were released in $136 \mathrm{~h}^{52}$

On the other hand, the PEG-coated $\mathrm{Fe}_{3} \mathrm{O}_{4}$ hollow spheres were used in an IBU delivery system. Hence, they designed and synthesized PEG-modified $\mathrm{Fe}_{3} \mathrm{O}_{4}$ hollow core/shell hierarchical nanostructures by a solvothermal process (preparation of the precursor) combined with subsequent thermal treatment. Similar to previous work, the samples were used for IBU delivery. After 6 h, $43 \%$ of the loaded IBU drug was released, and $78 \%$ was released after $24 \mathrm{~h}$; then, the drug release rate decreased and reached a value of $87 \%$ after $48 \mathrm{~h}$. However, the drug release rate of the IBU-uncoated $\mathrm{Fe}_{3} \mathrm{O}_{4}$ system was higher than that of the IBU-PEG-coated $\mathrm{Fe}_{3} \mathrm{O}_{4}$ system. In the first $6 \mathrm{~h}$, about $53 \%$ of the loaded IBU was released, and $77 \%$ was released in $12 \mathrm{~h}$; a value of $86 \%$ was reached after $24 \mathrm{~h}$, which is

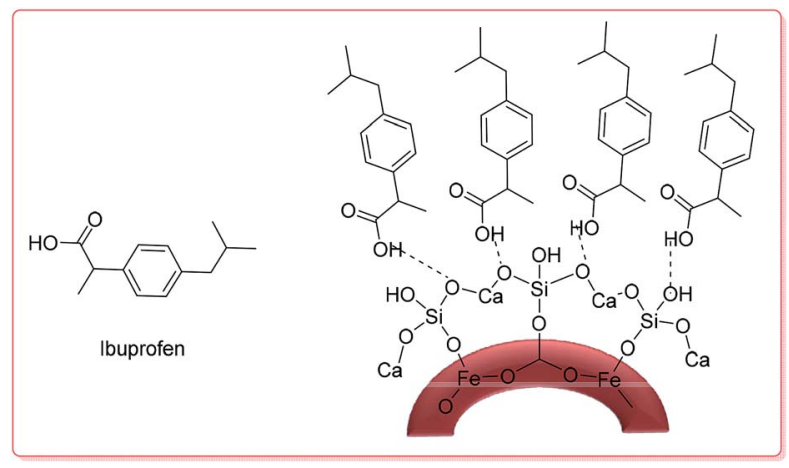

Scheme 2 The structure of IBU-MSCN. ${ }^{50}$ due to the formation of new hydrogen bonds between the hydroxyl groups of PEG and the carboxyl groups of the IBU molecules in the IBU-PEG-coated $\mathrm{Fe}_{3} \mathrm{O}_{4}$ system (Fig. S1a and $\mathrm{b} \dagger) .{ }^{53}$

Xia and coworkers synthesized $\mathrm{Fe}_{3} \mathrm{O}_{4}$ hollow magnetic core/ mesoporous shell (HMMS) structures using carboxylic polystyrene (PS) latex as a hard template that was enclosed within a silica shell via a sol-gel process (Fig. S2 $\dagger$ ). ${ }^{54}$ Then, HMMS was applied as a carrier for IBU delivery under an external magnetic field. The amount of IBU drug adsorbed by HMMS was about $20 \mathrm{mg} \mathrm{mL}^{-1}$. This sample was named HMMS-3-IBU-20, where 3 is the sample number and 20 is the concentration of IBU solution. The IBU release from the HMMS-3-IBU-20 system over a $50 \mathrm{~h}$ period in phosphate buffered saline solution ( $\mathrm{pH} 7.4$ ) was studied. Generally, $48 \%$ of the IBU was released from HMMS-3 after $10 \mathrm{~h}$, and over $70 \%$ of IBU was released at the end of the $50 \mathrm{~h}$ period (Fig. $\mathrm{S} 3 \dagger){ }^{54}$

In a different method, Zhu et al. designed the in situ growth of $\mathrm{Cu}_{3}$ (BTC $)_{2}$ nanomagnetic particles based on the polymerization of a methyl methacrylate (PMMA@ $\mathrm{Fe}_{3} \mathrm{O}_{4} / \mathrm{Cu}_{3}(\mathrm{BTC})_{2}$ ) hybrid hollow sphere metal framework (MOF) induced by onepot Pickering emulsion; these nanoparticles were used as a carrier in IBU delivery (Fig. S4†). Additionally, the average size of the IBU molecule $(0.5 \times 1.0 \times 0.8 \mathrm{~nm})$ is exceptionally close to the edge lengths of the square channels in $\mathrm{Cu}_{3}(\mathrm{BTC})_{2}(0.95$ $\mathrm{nm})$. Moreover, the drug was slowly released from $n$-hexane solution by magnetic separation within $15 \mathrm{~h}$ at $37^{\circ} \mathrm{C}$. The IBU release was complete after a period of $7 \mathrm{~h}$ at a higher temperature $\left(45^{\circ} \mathrm{C}\right) .{ }^{55}$

Another rattle-type $\mathrm{HMMS}$ with $\mathrm{Fe}_{3} \mathrm{O}_{4}$ nanoparticles encapsulated in the cores of mesoporous silica microspheres was successfully synthesized by Zhao et $a l .{ }^{56}$ Importantly, this structure has the merits of both enhanced drug-loading capacity and significant magnetization strength. The asprepared HMMSs recognize a relatively high storage capacity of up to $302 \mathrm{mg}$ per $\mathrm{g}$ of carrier when IBU is used as a model drug, and the IBU-HMMS system has sustained-release properties which follow Fick's law. ${ }^{56}$ Fig. 2 shows the IBU release

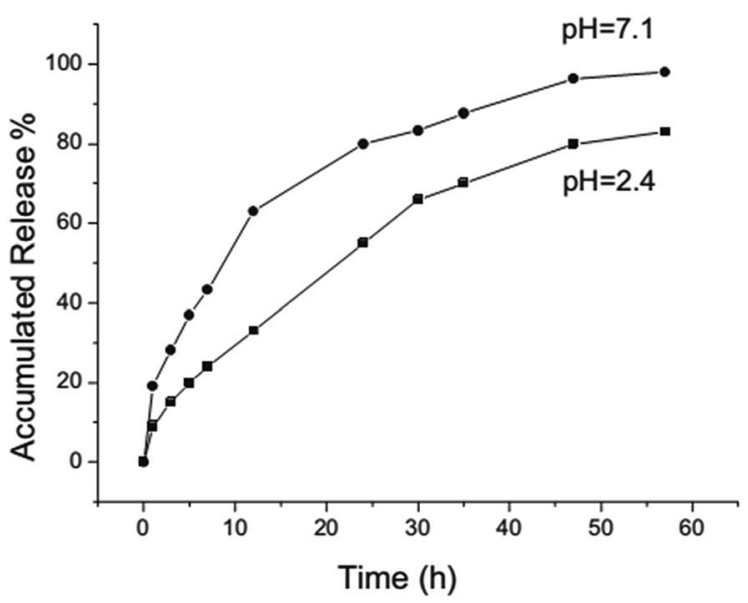

Fig. 2 IBU release processes from the HMMS system in a neutral solution $(\mathrm{pH} 7.1)$ and an acidic solution $(\mathrm{pH} 2.4){ }^{56}$ 
behaviour from the system over a $57 \mathrm{~h}$ period in neutral $(\mathrm{pH} 7.1)$ and acidic ( $\mathrm{pH}$ 2.4) solutions. Importantly, burst release occurs within $20 \mathrm{~h}$ from the HMMSs system at different $\mathrm{pH}$ values; then, sustained release follows. Furthermore, the IBU release rate in the neutral solution $(\mathrm{pH}$ 7.1) was faster than that in the acidic solution ( $\mathrm{pH}$ 2.4) (Fig. 2).

As a hollow hybrid carrier, super paramagnetic polyelectrolyte hybrid hollow microspheres ((CS/Fe $\left.\mathrm{O}_{4}-\mathrm{CA}\right)_{3}-\mathrm{CS}-$ $\mathrm{NHCH}_{2}-\mathrm{PEG}$ ) were synthesized and reported by Zhao and coworkers (Fig. 3). ${ }^{57}$ This system was used for IBU delivery, and the profile release behaviour in SBF was considered.

The drug loading capacities of $\left(\mathrm{CS} / \mathrm{Fe}_{3} \mathrm{O}_{4}-\mathrm{CA}\right)_{3}$ and (CS/ $\left.\mathrm{Fe}_{3} \mathrm{O}_{4}-\mathrm{CA}\right)_{3}-\mathrm{CS}-\mathrm{NHCH}_{2}-\mathrm{PEG}$ were found to be about 157 and $185 \mathrm{mg}$ of drug per $\mathrm{g}$ of carrier, while the IBU capacity of (CS/ $\left.\mathrm{Fe}_{3} \mathrm{O}_{4}-\mathrm{CA}\right)_{3}-\mathrm{CS}-\mathrm{NHCH}_{2}-\mathrm{PEG}$ was slightly higher than that of $\left(\mathrm{CS} / \mathrm{Fe}_{3} \mathrm{O}_{4}-\mathrm{CA}\right)_{3}$ due to hydrogen bonds between the hydroxyl groups of PEG and the carboxyl groups of the IBU drug. Therefore, the cumulative release rates of $\left(\mathrm{CS} / \mathrm{Fe}_{3} \mathrm{O}_{4}-\mathrm{CA}\right)_{3}-\mathrm{CS}-$ $\mathrm{NHCH}_{2}-\mathrm{PEG}$ and the $\left(\mathrm{CS} / \mathrm{Fe}_{3} \mathrm{O}_{4}-\mathrm{CA}\right)_{3}$ hollow carrier in PBS solution at pH 7.4 at $37{ }^{\circ} \mathrm{C}$ for $60 \mathrm{~h}$ were calculated to be about $91.78 \%$ and $81.52 \%$, respectively (Fig. 4 ). ${ }^{57}$

Zhou and co-workers synthesized porous magnetic hollow silica nanospheres (MHSNs) as a hollow carrier for IBU with drug loading capability. Thus, the uptake capacities of IBU were $14.21 \%$ for the hollow carriers with a pore size of $3.7 \mathrm{~nm}$ and $8.7 \%$ for those with a pore size of $1.5 \mathrm{~nm}$, which was determined by UV-Vis analysis.

The release test was carried out in $50 \mathrm{~mL}$ of PBS (pH 7.4). About $15 \%$ of the IBU was released from the hollow carrier with a 3.7 pore size in the first $0.5 \mathrm{~h}$; then, about $42 \%$ was released overnight. However, in the other case with a pore size of $1.5 \mathrm{~nm}$, more than $80 \%$ of the IBU was released in the first half-hour (Fig. S5†). ${ }^{58}$

In another publication, Lu et al. successfully prepared magnetic $\mathrm{Fe}_{3} \mathrm{O}_{4}$ /calcium silicate mesoporous nanocomposites (MMCNs) using a two-liquid-phase system by ultrasonic irradiation. According to the UV-Vis results, about $1.03 \mathrm{~g}$ of drug per $g$ of carrier could be loaded into the magnetic hollow spheres; also, the drug was slowly released from the MMCNs. ${ }^{59}$

Recently, Yang and co-workers studied the aminofunctionalized hollow $\mathrm{Fe}_{3} \mathrm{O}_{4} / \mathrm{SiO}_{2}$ core-shell structure and its

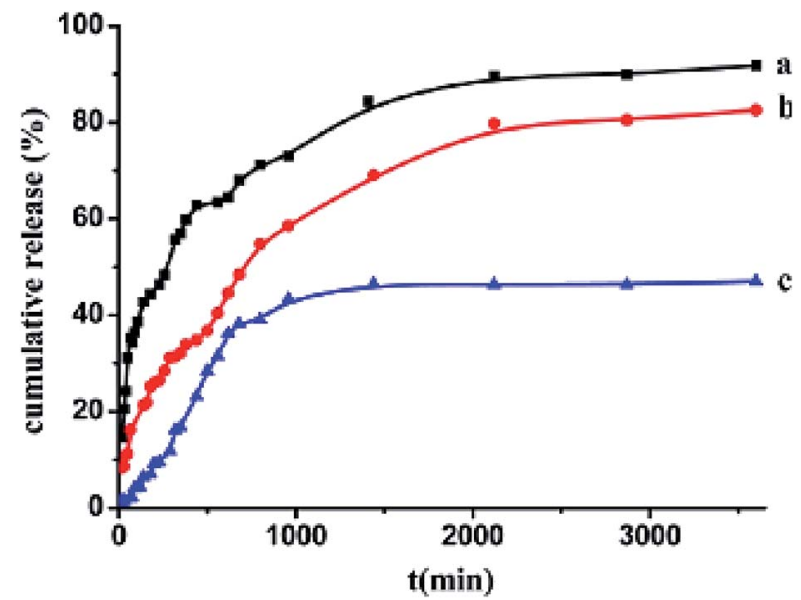

Fig. 4 Cumulative ibuprofen release rates from the drug-adsorbed super paramagnetic polyelectrolyte hybrid hollow microspheres (CS/ $\left.\mathrm{Fe}_{3} \mathrm{O}_{4}-\mathrm{CA}\right)_{3}-\mathrm{CS}$ in $\mathrm{pH} 7.4$ phosphate buffer at $37{ }^{\circ} \mathrm{C}$ (a) and from the biocompatible $\left(\mathrm{CS} / \mathrm{Fe}_{3} \mathrm{O}_{4}-\mathrm{CA}\right)_{3}-\mathrm{CS}-\mathrm{NH}-\mathrm{CH}_{2}-\mathrm{PEG}$ hollow microspheres in phosphate buffer at pH 7.4 (b) or 1.8 (c) at $37^{\circ} \mathrm{C}$, respectively. ${ }^{57}$

modification with folic acid (FA) as a carrier for IBU delivery (Fig. S6 $\dagger$ ). ${ }^{60}$ The loading capacities of IBU for $\mathrm{Fe}_{3} \mathrm{O}_{4}-\mathrm{SiO}_{2}-\mathrm{NH}_{2}$ and $\mathrm{Fe}_{3} \mathrm{O}_{4}-\mathrm{SiO}_{2}-\mathrm{NHFA}$ were $23.3 \%$ and $27.7 \%$, respectively. However, due to the higher specific surface area of $\mathrm{Fe}_{3} \mathrm{O}_{4}-\mathrm{SiO}_{2}-$ NHFA than of $\mathrm{Fe}_{3} \mathrm{O}_{4}-\mathrm{SiO}_{2}-\mathrm{NH}_{2}$, the IBU storage capacity was suitable. Further, according to its release behaviours in PBS solution ( $\mathrm{pH} 7.4$ ), the release rate of the $\mathrm{Fe}_{3} \mathrm{O}_{4}-\mathrm{SiO}_{2}-\mathrm{NHFA}$ carrier $(17.89 \%)$ was lower than that of $\mathrm{Fe}_{3} \mathrm{O}_{4}-\mathrm{SiO}_{2}-\mathrm{NH}_{2}$ $(37.23 \%)$ because of the existence of interactions between the carboxyl groups of IBU and the - $\mathrm{CONH}$ groups and hydroxyl groups on $\mathrm{Fe}_{3} \mathrm{O}_{4}-\mathrm{SiO}_{2}-\mathrm{NHFA}$ (Fig. S7†). ${ }^{60}$

In an interesting study, raspberry-like nanomagnetic hollow silica nanospheres (PS@ $\mathrm{Fe}_{3} \mathrm{O}_{4} @ \mathrm{SiO}_{2}$ ) were used as an IBU carrier by Wang et al. ${ }^{61}$ According to their results, the suitable IBU molecule was introduced into all the pore volumes of the carrier $\left(1.79,1.33\right.$ and $\left.1.18 \mathrm{~cm}^{3} \mathrm{~g}^{-1}\right)$; then, about $55 \%$ to $70 \%$ of loaded IBU was released slowly in all cases after $20 \mathrm{~h}$ (Table 1).

3.2.1.2. Ferrites. Yang et al. synthesized magnetic $\mathrm{ZnFe}_{2} \mathrm{O}_{4}$ hollow microsphere silica shells (MZHM-MSS- $\mathrm{NH}_{2}$ ),
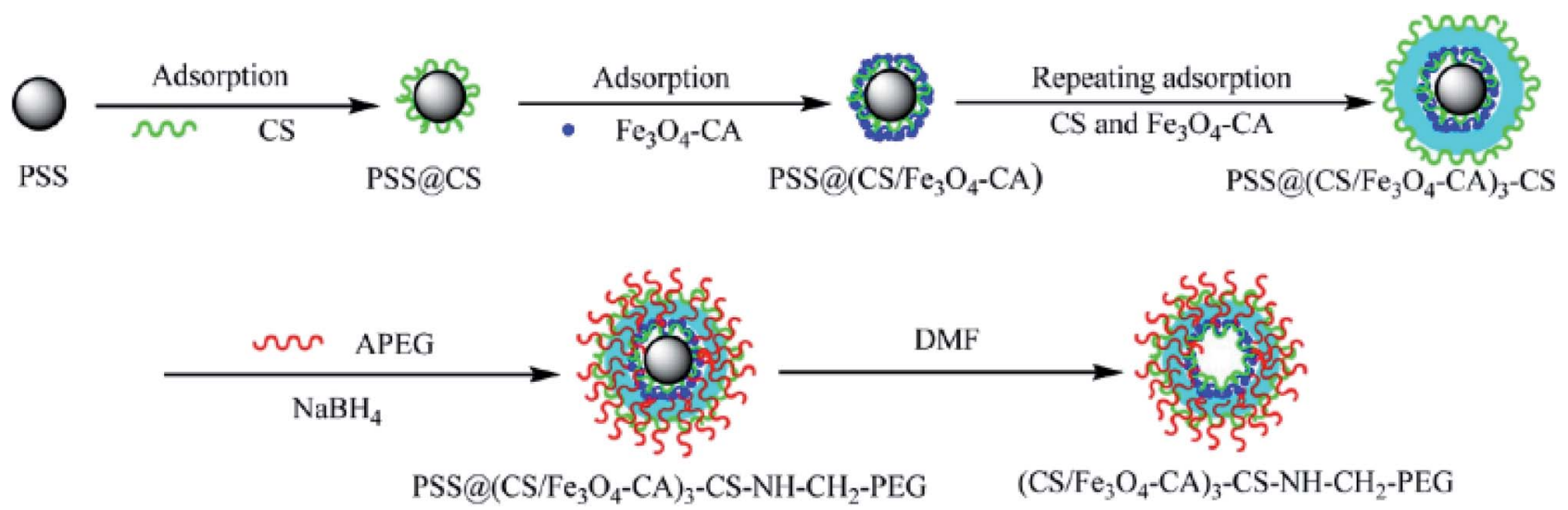

Fig. 3 Schematic of the preparation of superparamagnetic polyelectrolyte hybrid hollow microspheres. ${ }^{57}$ 
Table 1 The textural properties of magnetic-hollow silica nanospheres ${ }^{61}$

\begin{tabular}{llllll}
\hline Sample & $\begin{array}{l}\mathrm{NH}_{4} \mathrm{OH} \\
(\mathrm{mL})\end{array}$ & TEOS $(\mathrm{mL})$ & BET $\left(\mathrm{m}^{2} \mathrm{~g}^{-1}\right)$ & $\begin{array}{l}\text { Total pore volume } \\
\left(\mathrm{cm}^{3} \mathrm{~g}^{-1}\right)\end{array}$ & Pore size distribution \\
\hline $1^{a}$ & 2 & 1 & 471 & 1.79 & 3.5 to 5.5 \\
$2^{b}$ & 4 & 1 & 307 & 1.33 & 3.5 to 5.5 \\
$3^{c}$ & 4 & 1.5 & 265 & 1.18 & 3.5 to 5.5
\end{tabular}

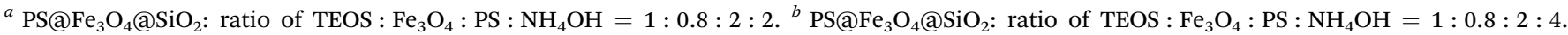
${ }^{c} \mathrm{PS} @ \mathrm{Fe}_{3} \mathrm{O}_{4} @ \mathrm{SiO}_{2}$ : ratio of TEOS $: \mathrm{Fe}_{3} \mathrm{O}_{4}: \mathrm{PS}: \mathrm{NH}_{4} \mathrm{OH}=0.5: 0.8: 2: 4$.

functionalized them with folic acid (MZHM-MSS-NHFA) and then used them as an IBU carrier for controlled release (Fig. S8 + ). ${ }^{62}$ The IBU storage capacities of MZHM-MSS- $\mathrm{NH}_{2}$ and MZHM-MSS-NHFA were reported to be $16.9 \%$ and $22.2 \%$, respectively. The drug release process into a PBS solution at $37^{\circ} \mathrm{C}$ was studied. After $48 \mathrm{~h}$, the release amounts of IBU from the MZHM-MSS- $\mathrm{NH}_{2}$ and MZHM-MSS-NHFA systems were $16.90 \%$ and $12.11 \%$, respectively, which is due to ionic interactions of the IBU carboxyl groups with the amine groups of MZHM-MSS- $\mathrm{NH}_{2}$ (Fig. S9†). ${ }^{62}$

Zhang and co-workers studied multiple shell hollow $\mathrm{CoFe}_{2} \mathrm{O}_{4}$ as a nanocarrier for IBU delivery. The drug loading capacity of the as-prepared $\mathrm{CoFe}_{2} \mathrm{O}_{4}$ was $12.5 \%$, which was attributed to the large specific surface area, mesopores and interconnected macropores of the carrier. The release behaviours of IBU from the drug-loaded magnetic mesoporous calcium nanocomposites (DL-MSHCSs) was considered in PBS over $48 \mathrm{~h}$; it was faster than the release from drug-loaded solid carbon particles (DL-SCPs, Fig. 5). ${ }^{63}$

3.2.2. Sodium meclofenamate (SMF). Nonsteroidal antiinflammatory drugs, such as aspirin, sodium diclofenac, piroxicam, tenoxicam, ibuprofen, and sodium meclofenamate, are widely sold and consumed around the world due to their effectiveness, low price and availability. ${ }^{64}$

In particular, sodium meclofenamate $\left(\mathrm{p} K_{\mathrm{a}}=4.39\right.$; soluble in water, ethanol, DMSO and DMF) is a very useful drug for the symptomatic treatment of moderate pain, several forms of arthritis, dysmenorrhea and menorrhagia. ${ }^{65}$

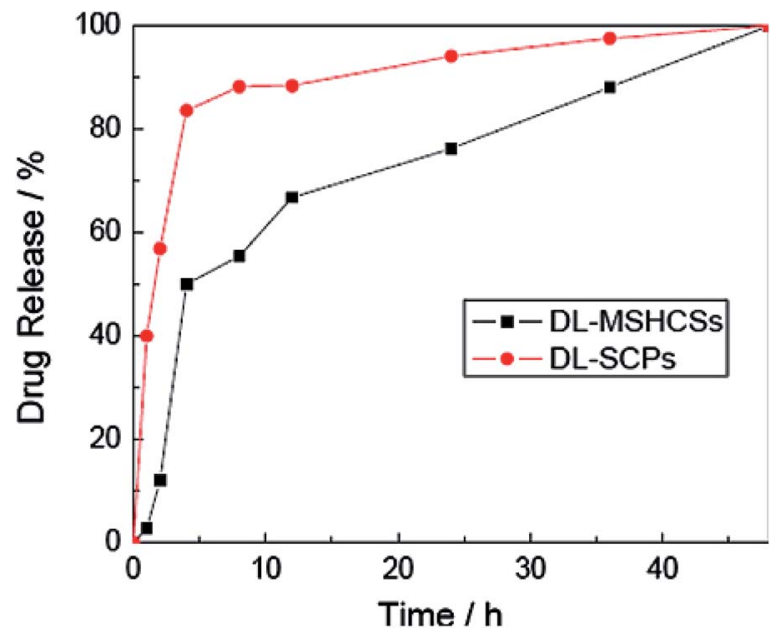

Fig. 5 Drug release behaviour of DL-MSHCSs and DL-SCPs. ${ }^{63}$
Lately, Alan and co-workers effectively synthesized hollow magnetic nanocapsules with a high specific surface area as a carrier for SMF loading and significant drug release in vivo. ${ }^{66}$ SMF was successfully loaded onto the surface of the magnetic nanocapsules; about $18 \%$ was loaded after $18 \mathrm{~h}$. Then, the drug release rate of the SMF loaded onto a sample under physiological conditions in PBS buffer at pH 7.2 was studied; about $45 \%$ of the loaded SMF was successfully released after 6 hours in aqueous suspension. ${ }^{66}$

\subsection{Antibiotics}

3.3.1. Cefradine. Cefradine (Cef) is a broad-spectrum antibiotic that is active against a broad variety of bacteria. It is used to treat bacterial infections such as urinary tract infections, skin infections, chest and throat infections, and ear infections. ${ }^{67}$ Notably, cefradine is less allergenic than penicillin as an antibiotic for some patients. In this regard, $\mathrm{Li}$ and co-workers synthesized hollow $\mathrm{Fe}_{3} \mathrm{O}_{4}$ L-cysteine (Cys)-capped polyelectrolyte $\left(\mathrm{Fe}_{3} \mathrm{O}_{4} / \mathrm{PE}_{5} / \mathrm{CdTe} / \mathrm{PE}_{1}\right)$ as a carrier for Cef delivery. ${ }^{68}$

The total drug loading amount of Cef was $73 \mathrm{wt} \%(730 \mathrm{mg}$ of Cef per $\mathrm{g}$ of carrier). As a result, the Cef release rates of magnetic and fluorescent hollow composites-cefradine (MFHC-Cef) in three simulated physiological release media with $\mathrm{pH} 2$ (simulated gastric fluid), $\mathrm{pH} 7.4$ (simulated blood fluid) and $\mathrm{pH} 8.94$ (simulated intestinal fluid) were studied; the particles exhibit more compact structures in acidic medium than in basic medium, which leads to differences in their drug permeability and drug release rates (Fig. S10 and S11†). ${ }^{68}$

3.3.2. Vancomycin. Vancomycin (VAN) is a natural antibiotic that is used for the treatment of numerous bacterial infections. ${ }^{69}$ Hollow magnetic hydroxyapatite $\mathrm{Ca}_{10}\left(\mathrm{PO}_{4}\right)_{6}(\mathrm{OH})_{2}$, HAp microspheres with hierarchically mesoporous structures were fabricated by Lin et al. ${ }^{70}$ and their VAN loading and release properties were studied (Scheme 3).

The VAN loading amount of the hollow microspheres reached 28.84 to $35.92 \mathrm{mg} \mathrm{g}^{-1}$, which was higher than that of traditional hollow magnetic hydroxyapatite nanoparticles, due to the formation of stronger affinity hydroxyl groups in HAp and VAN molecules through H-bond interactions. The initial burst release of VAN in the first $9 \mathrm{~h}$ at $\mathrm{pH} 7.4$ was around $19 \mathrm{wt} \%$ in PBS; VAN was then released completely during the next 2 days (Fig. S12†)..$^{70}$ Table 2 displays the results of the investigation of the capability of the fabricated hollow magnetic HAp microspheres to act as drug carriers using VAN as a model drug. The fabricated hollow magnetic HAp microspheres with higher $S_{\mathrm{BET}}$ 


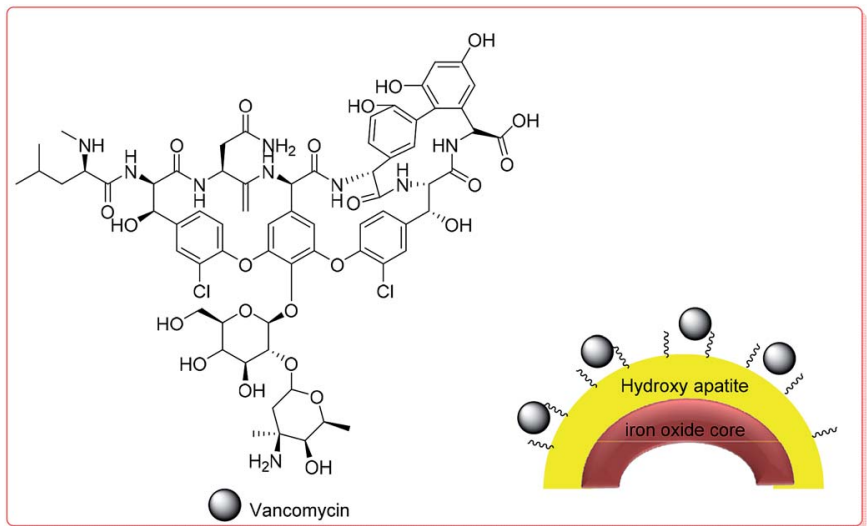

Scheme 3 The structure of VAN-HAp. ${ }^{70}$

Table 2 The $\mathrm{Fe}_{3} \mathrm{O}_{4}$ amounts, specific surface areas $\left(S_{\mathrm{BET}}\right)$, drug loading amounts (DLA) and drug loading efficiencies (DLE) of the control HAp nanoparticles (SO) and hollow microspheres (S1) and the fabricated hollow magnetic HAp microspheres (S2-S4) ${ }^{70}$

\begin{tabular}{lllll}
\hline Sample & $\begin{array}{l}\mathrm{Fe}_{3} \mathrm{O}_{4} \text { amount } \\
(\mathrm{wt} \%)\end{array}$ & $S_{\text {BET }}\left(\mathrm{m}^{2} \mathrm{~g}^{-1}\right)$ & DLA $\left(\mathrm{mg} \mathrm{g}^{-1}\right)$ & DLE (\%) \\
\hline S0 & - & 11.17 & $19.08 \pm 2.7$ & $47.7 \pm 6.75$ \\
S1 & - & 34.87 & $35.92 \pm 0.12$ & $89.8 \pm 0.28$ \\
S2 & 3.97 & 41.55 & $30.24 \pm 0.11$ & $75.6 \pm 0.28$ \\
S3 & 15.38 & 52.32 & $30.16 \pm 0.59$ & $75.4 \pm 1.41$ \\
S4 & 40.78 & 67.26 & $28.86 \pm 1.95$ & $72.2 \pm 4.88$
\end{tabular}

could successfully provide much more active sites to adsorb higher amounts of the VAN drug. ${ }^{70}$

3.3.3. Enrofloxacin. Enrofloxacin hydrochloride (ENR) is a bactericidal agent that has demonstrated significant postantibiotic effects on both Gram-negative and positive bacteria and is active in both stationary and growth phases of bacterial replication. Lately, Liu and co-workers effectively synthesized yolk-shell structured magnetic hollow mesoporous silica nanospheres (MHMS) with high specific surface areas as a carrier for ENR loading and significant "on-off”' drug release in vitro under intermittent AMF. ENR was successfully loaded into the pores on the surface of the MHMS. The relative release rate of MHMS in a consecutive "on-off" operation under the external AMF was fast, with a coincident capacity of $60.83 \% \pm$ $3.74 \%$ within $24 \mathrm{~h}$ (Fig. 6). ${ }^{71}$

\subsection{Anticancer}

3.4.1. Doxorubicin. Doxorubicin (DOX), also called doxorubicin hydrochloride or adriamycin, is a chemotherapy agent that is frequently used to treat cancers $^{72,73}$ such as breast cancer, ${ }^{74}$ bladder cancer, ${ }^{74}$ Kaposi's sarcoma ${ }^{72}$ and lymphoma. ${ }^{72}$ It is often used together with other chemotherapy agents. Xu et al. synthesized hollow-structured magnetic particles (HMSPs) via casein micelle (CM)-facilitated microwave irradiation. ${ }^{75}$ Moreover, the particles were used as a carrier for DOX as an anti-cancer drug. The DOX-loaded HMSPs showed 15.2 wt\% viability for $2.5 \mathrm{mg} \mathrm{mL}^{-1}$. Then, DOX was released in vitro from

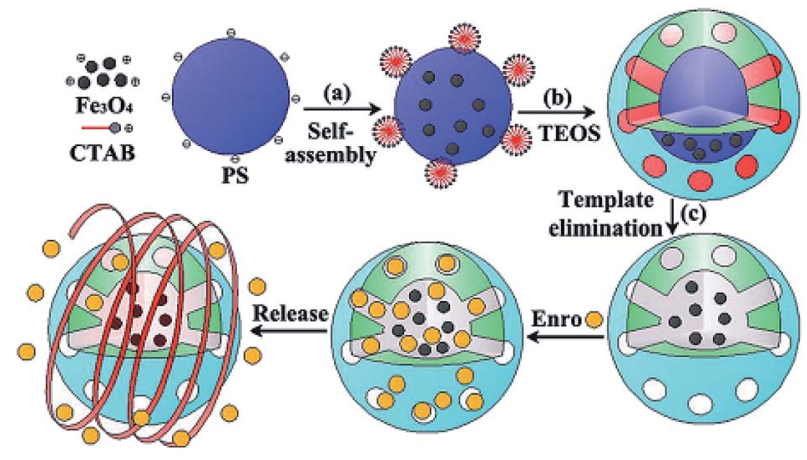

Fig. 6 Schematic of the ENR loading and release of MHMS. ${ }^{71}$

the carrier via pH-responsive pathways, with up to $83 \%$ DOX release in acidic environments ( $\mathrm{pH} 4.0$ and 5.0), whereas low (18\%) DOX release occurred at neutral $\mathrm{pH}(\mathrm{pH} 7.4)$ within $48 \mathrm{~h}$, indicating minimal premature drug release (Fig. S13 and $\mathrm{S} 14 \dagger){ }^{75}$

In another report, Zhu et al. considered a novel super paramagnetic hollow sphere core-shell structure to study the effects of loading and release of drugs on the surface of nanoparticles. Notably, this delivery method provided a steady aqueous dispersion of hydrophobic drugs with a hydrodynamic size of about $191.9 \pm 2.6 \mathrm{~nm}$. DOX was used as a model drug; the endosomal/lysosomal acidic environment enhanced the solubility and drug release of the basic drug. The DOX-loading was measured by UV-Vis spectrometry, and SPIO exhibited a good loading capacity of $10.1 \pm 2.5 \mathrm{wt} \%$ of drug at $\mathrm{pH}$ 7.4. Then, an investigation of the in vitro DOX release from the superparamagnetic iron oxide (SPIO) nanoshells was carried out in PBS for $24 \mathrm{~h}$ (pH 7.4); the loading was $26.3 \pm 1.8 \mathrm{wt} \% .^{76}$ On the other hand, Park and co-workers established an effective synthesis of monodisperse hollow composite poly(methacrylic acid/ethylene glycol dimethacrylate) $/ \mathrm{Fe}_{3} \mathrm{O}_{4}$ microcapsules (pol$\mathrm{y}(\mathrm{MAA} / \mathrm{EGDMA}) / \mathrm{Fe}_{3} \mathrm{O}_{4}$ ), which were studied as a drug delivery system (Fig. S15 $\dagger$ ). ${ }^{77}$ DOX as a model drug was loaded onto the microcapsules, and the successful controlled delivery system enabled $84.6 \%$ loading efficiency of the total DOX. The release rate of sample drug from the composite microcapsules was $\mathrm{pH}$ dependent in acidic solution because of the weaker electrostatic binding between the anionic carboxyl groups and cationic DOX. Generally, $43.8 \mathrm{wt} \%$ of DOX was released in PBS solution at $\mathrm{pH}$ 2; a lower drug amount of $28.0 \mathrm{wt} \%$ was released at $\mathrm{pH} 4$. In contrast, at $\mathrm{pH} 7$, the release was quite low and remained principally constant $(9.5 \mathrm{wt} \%$ ) (Fig. $\mathrm{S} 16 \dagger) .{ }^{77}$

In addition to the modular approach, $\mathrm{Lu}$ and co-workers synthesized multi-functional hollow mesoporous silica nanocapsules with encapsulated iron oxide nanoparticles (IONPs) which were considered for a combination of hyperthermia and chemotherapy applications. ${ }^{78}$ Hence, DOX was loaded into the pores of the silica shells, with a capacity of $97 \mathrm{mg}$ of drug per $\mathrm{g}$ of carrier. The DOX release from synthesized nanocapsules with two different drug loading amounts was investigated at different $\mathrm{pH}$ values and under an alternating magnetic field (AMF). However, when DOX release under AMF excitation was 
applied, the nanocapsule suspension showed a fast magnetic field response at $43{ }^{\circ} \mathrm{C}$ for a sample with a concentration of $1.3 \mathrm{mg} \mathrm{mL}^{-1}$ within $7 \mathrm{~h}$ (Fig. 6, and 7). ${ }^{78}$

Recently, Cheng et al. synthesized $\mathrm{Fe}_{3} \mathrm{O}_{4} @ \mathrm{C}$ nanocapsules via a sacrificial-template method by coating $\mathrm{SiO}_{2}$ nanospheres with a $\mathrm{Fe}_{3} \mathrm{O}_{4} @ \mathrm{C}$ double-shell structure, followed by etching the $\mathrm{SiO}_{2}$ core under hydrothermal conditions. The nanocapsules exhibited a high loading capacity (1300 $\mathrm{mg} \mathrm{g}^{-1}$ for DOX), and the DOX loaded on the surface of the carbon shells showed $\mathrm{pH}$ dependent behavior. DOX release experiments were carried out at three different $\mathrm{pH}$ values of 7.4, 6.2 and 5.0. Accordingly, the drug release rate at $\mathrm{pH} 6.2$ was about two times faster than that at $\mathrm{pH} 7.4$ and was even faster at $\mathrm{pH} 5.0$ (Scheme 4$){ }^{79}$

The zeta potentials of the magnetic nanocapsules in solutions with different $\mathrm{pH}$ values were also measured; it was found that the surface of the particles was negatively charged at $\mathrm{pH}$ values higher than 3 , while at $\mathrm{pH} 5.0$ to 7.4, the ionization of the carboxyl groups on the hollow magnetic nanoparticles (HMNPs) formed $\mathrm{COO}^{-}$and the amino groups of DOX combined with the hydrogen ions to form $\mathrm{NH}_{3}{ }^{+}$. The electrostatic interactions of $\mathrm{COO}^{-}$and $\mathrm{NH}_{3}{ }^{+}$also contributed to the loading of DOX on the HMNPs. As the pH decreased from 7.4 to 5.0, the zeta potential of the HMNPs increased, which indicates that the surface of the HMNPs became less negative. On the other hand, drug release experiments carried out at $\mathrm{pH} 7.4$ can be used to simulate the behavior of DOX-HMNPs when they are injected into blood or enter the intracellular environment or the cytoplasm of normal cells. The release rate at $\mathrm{pH} 7.4$ is quite low (compared to the drug release experiment carried out at $\mathrm{pH} 6.2){ }^{79}$

Zhou et al. prepared monodispersed yolk-type $\mathrm{Au} @ \mathrm{Fe}_{3} \mathrm{O}_{4} @ \mathrm{C}$ nanospheres with hollow cores $50 \mathrm{~nm}$ in diameter by coating $\mathrm{Au} @ \mathrm{SiO}_{2}$ nanoparticles with $\mathrm{Fe}_{3} \mathrm{O}_{4}$ @C double layers followed by dissolving the $\mathrm{SiO}_{2}$ (Fig. 8). ${ }^{\mathbf{8 0}}$ The cytotoxicity of the nanospheres was evaluated by methyl thiazolyltetrazolium assay (MTT assay), which demonstrated their high biocompatibility. As a model drug, DOX was loaded into the yolk-type nanospheres and showed a high DOX loading content of $1237 \mathrm{mg}$ $\mathrm{g}^{-1}$. Moreover, the drug-loaded particles were divided into two groups to examine the release rates; one portion was subjected to magnetic stirring with near infrared irradiation, and the other portion was subjected to magnetic stirring at a constant rate at $37{ }^{\circ} \mathrm{C}$ at $\mathrm{pH} 7.4$.

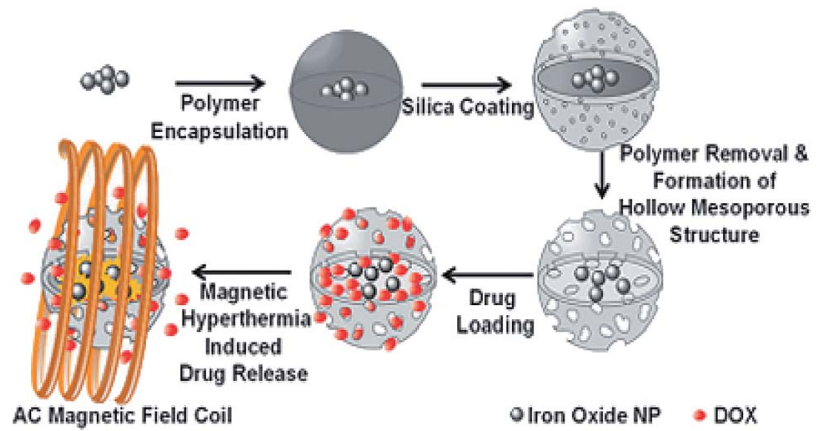

Fig. 7 Schematic of DOX loading and magnetic hyperthermiainduced release. ${ }^{78}$

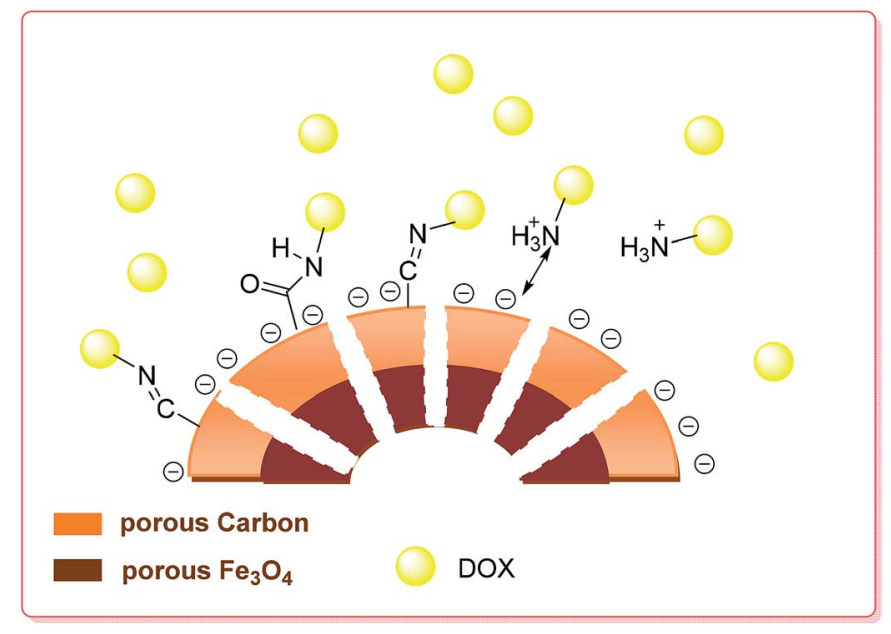

Scheme 4 Schematic of the preparation and drug loading of the porous hollow $\mathrm{Fe}_{3} \mathrm{O}_{4} \mathrm{OC}$ nanocapsules. ${ }^{79}$

According to the DOX release profiles in Fig. 9, the DOX$\mathrm{Au} @ \mathrm{Fe}_{3} \mathrm{O}_{4} @ \mathrm{C}$ system obviously demonstrates sustained release; the cumulative release percentage with irradiation of a NIR-laser (red, $60 \%$ ) was nearly $25 \%$ higher than that without laser irradiation (black, 35\%) after 100 h. ${ }^{80}$

Peng and co-workers synthesized hollow iron oxide hydroxide mesoporous silica spheres (FeOOH/HMSS-PEG) and studied their feasibility for in vitro drug delivery (Fig. S17†). The amount of DOX loaded onto the magnetic carrier was $237.1 \mu \mathrm{g}$ per $\mathrm{mg}$ of carrier in PBS solution. The protonated $-\mathrm{NH}_{2}$ groups of the drug became hydrophilic and more water-soluble in an acidic environment; thus, DOX was released completely at $\mathrm{pH}$ $6.5 .^{82}$

Ji and co-workers used DOX as an anticancer agent to study the drug delivery and release efficiency of $\mathrm{HPFe}_{3} \mathrm{O}_{4}$ @DDACMMPEG-FA (Fig. 10). The theoretical DOX loading contents were set at $5 \%, 10 \%$ and $50 \%$ and the obtained DOX loading efficiencies were $79.40 \%, 72.30 \%$ and $65.86 \%$, respectively. The DOX release

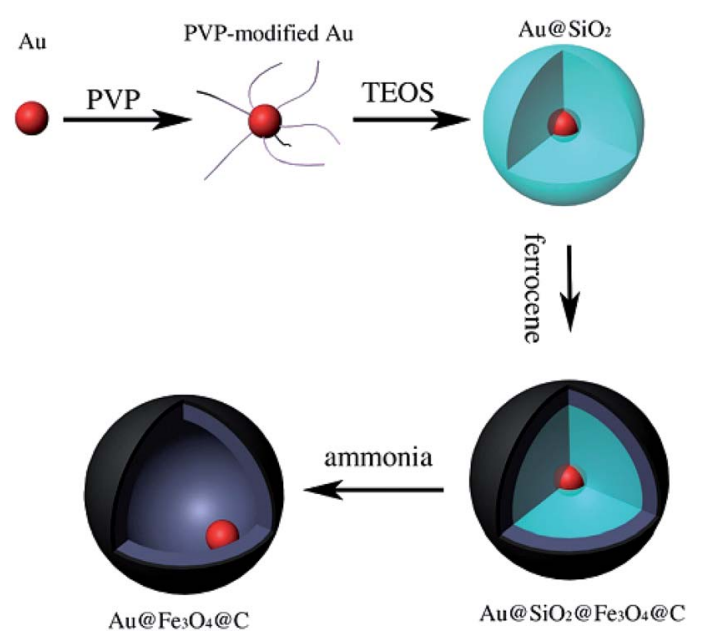

Fig. 8 Schematic of the preparation procedure of yolk-type $\mathrm{Au}_{\mathrm{aFe}} \mathrm{O}_{4} \mathrm{QC} .{ }^{80}$ 


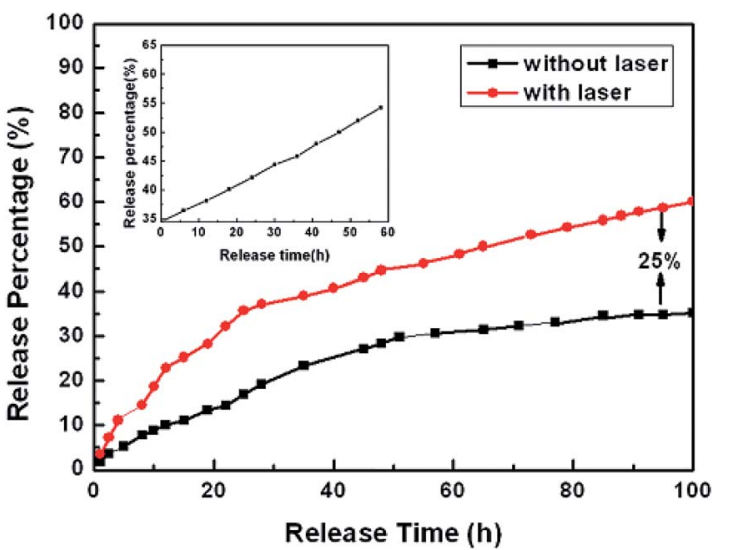

Fig. 9 In vitro release profiles of $\mathrm{DOX}-\mathrm{Au}\left(\mathrm{Fe}_{3} \mathrm{O}_{4}(\mathrm{aC}\right.$ nanoparticles with (red) and without (black) laser irradiation for $100 \mathrm{~h}$. Inset: further DOX release (black) on the balance for another $60 \mathrm{~h}$ with laser radiation. ${ }^{80}$

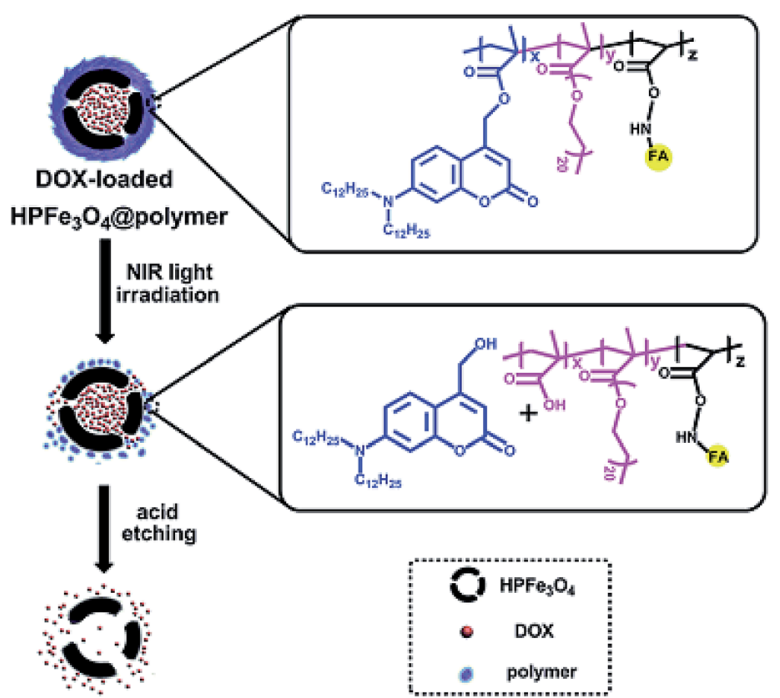

Fig. 10 Schematic of the fabrication of $\mathrm{HPFe}_{3} \mathrm{O}_{4}$ (aDDACMM-PEG-FA and its controlled release upon NIR light exposure. ${ }^{81}$

process was considered by UV-Vis spectroscopy at $\lambda=385 \mathrm{~nm}$. Moreover, the in vitro DOX release of the nanocarrier was studied under NIR light exposure at $37^{\circ} \mathrm{C}$. Meanwhile, much more DOX was released from the hollow carriers in the $\mathrm{pH} 5.0$ solution than in the $\mathrm{pH} 7.0$ solution (about 20\% increase overnight). ${ }^{81}$

To study the folate targeting and magnetic response effects of the drug delivery system, folate modification of HMCNCs was developed by Li et al.$^{83}$ According to the TGA analysis results, the total weight loss observed for folate-HMCNCs was approximately $10 \mathrm{wt} \%$; similarly, the weight loss behavior of DOX loaded on folate-HMCNCs enabled the calculation of the DOX in the carrier as approximately $24 \mathrm{wt} \%$. Thus, about $69.1 \%$, $76.4 \%$ and $79.8 \%$ of the DOX in $\mathrm{Na}_{3} \mathrm{Cit} / \mathrm{H}_{3} \mathrm{C}$ in buffer solution at $\mathrm{pH} 5$ was released during $48 \mathrm{~h}$ from folate-HMCNCs-DOX samples with $0.20,0.29$, and $0.36 \mathrm{~cm}^{3} \mathrm{~g}^{-1}$ shell-pore volumes, respectively. ${ }^{83}$

Recently, Zhu and co-workers synthesized folate-conjugated $\mathrm{Fe}_{3} \mathrm{O}_{4} @ \mathrm{SiO}_{2}$ hollow spheres $\left(\mathrm{Fe}_{3} \mathrm{O}_{4} @ \mathrm{SiO}_{2}\right.$-FA $)$ to study the loading and subsequent release of DOX as an anticancer drug in $\mathrm{Fe}_{3} \mathrm{O}_{4} @ \mathrm{SiO}_{2}$ and $\mathrm{Fe}_{3} \mathrm{O}_{4} @ \mathrm{SiO}_{2}$-FA hollow spheres (Fig. S18 $\dagger$ ). The DOX loading efficiencies of $\mathrm{Fe}_{3} \mathrm{O}_{4} @ \mathrm{SiO}_{2}$ and $\mathrm{Fe}_{3} \mathrm{O}_{4} @ \mathrm{SiO}_{2}-$ FA were determined to be $76.6 \%$ and $54 \%$, respectively. However, the DOX loading capacities in $\mathrm{Fe}_{3} \mathrm{O}_{4} @ \mathrm{SiO}_{2}$ and $\mathrm{Fe}_{3}-$ $\mathrm{O}_{4} @ \mathrm{SiO}_{2}$-FA were 27 and 38.3 ( $\mu \mathrm{g}$ per mg of carrier), respectively. On the other hand, fast release of DOX from the $\mathrm{Fe}_{3} \mathrm{O}_{4} @ \mathrm{SiO}_{2}$ and $\mathrm{Fe}_{3} \mathrm{O}_{4} @ \mathrm{SiO}_{2}$-FA spheres occurred within $8 \mathrm{~h}$ in PBS (pH 7.4) at $37{ }^{\circ} \mathrm{C}$. However, the release rate of the $\mathrm{Fe}_{3}$ $\mathrm{O}_{4} @ \mathrm{SiO}_{2}$-FA spheres was slower than that of the $\mathrm{Fe}_{3} \mathrm{O}_{4} @ \mathrm{SiO}_{2}$ spheres (Fig. S19†). ${ }^{84}$

Recently, the use of polymers was found to be proficient to efficiently control carried drugs and remarkably limit the side effects and waste of drugs. ${ }^{85}$ Among these, poly $(N$-isopropylacrylamide) (PNIPAM) is a thermal-responsive polymer that exhibits a lower critical solution temperature (LCST) and is a suitable candidate for the fabrication of organic-inorganic hollow sphere carriers. Liu and co-workers described the drug delivery properties of the PNIPAM $/ \mathrm{Fe}_{3} \mathrm{O}_{4}-\mathrm{ZnS}$ hybrid hollow spheres for DOX as an anticancer agent (Fig. S20 $\dagger$ ).

The concentration of DOX was measured by a UV-Vis spectrometer $(480 \mathrm{~nm})$; the loading capacity of DOX in the carrier was found to be about $70 \mu \mathrm{g}$ per mg of carrier, and the DOXloading efficiency was $35.5 \%$. However, according to the drug release of DOX from the hybrid hollow spheres in PBS at pH 7 at different temperatures $\left(25^{\circ} \mathrm{C}, 37^{\circ} \mathrm{C}\right.$, and $\left.42{ }^{\circ} \mathrm{C}\right)$, about $20.9 \%$ cumulative DOX was released after $51 \mathrm{~h}$ at $25^{\circ} \mathrm{C}$; meanwhile, the release increased to $25.6 \%$ at $37^{\circ} \mathrm{C}$ and $29.1 \%$ at $42{ }^{\circ} \mathrm{C}$. Due to the expulsion of hydrophobically bound water from the polymer chains, the DOX release was faster at higher temperatures than at $25{ }^{\circ} \mathrm{C}$ (Fig. S21†). ${ }^{86}$ The effects of a hollow hybrid nanogel system (poly(AA-co-MEA)-g-mPEG/PNIPA) as a carrier were studied on the delivery and release of DOX as a drug agent. ${ }^{87}$ The results showed a high DOX loading efficiency (88.3\%) and DOX loading capacity (9.6 wt \%) for the hollow hybrid nanogels. The in vitro release of the loaded DOX from the hybrid nanogels was dependent on both $\mathrm{pH}$ and temperature. Furthermore, among various $\mathrm{pH}$ values (7.4, 5 and 4), remarkably enhanced drug release $(>50 \%)$ at $\mathrm{pH} 5$ was obtained at $37^{\circ} \mathrm{C}$ over a period of $24 \mathrm{~h}$.

Huang et al. synthesized tubular silica particles with hollow/ porous structures based on $\mathrm{Fe}_{3} \mathrm{O}_{4}$ MNPs and hyaluronic acid and then used them as a DOX carrier for controlled release. ${ }^{88}$ The DOX storage capacity of the nanocarrier was reported to be $18.7 \%$. The drug release process into PBS solution at $37^{\circ} \mathrm{C}$ was studied. The nanocarrier-DOX revealed sustained drug release behaviour over $36 \mathrm{~h}$, reaching $23 \%$ and $55 \%$ of the initial DOX loading amount at $\mathrm{pH} 7.4$ and 5.5 , respectively. ${ }^{88}$

Recently, Zhang and co-workers successfully synthesized hollow mesoporous silica nanochains with movable maghemite cores $\left(\gamma-\mathrm{Fe}_{2} \mathrm{O}_{3} @ \mathrm{mSiO}_{2}\right)$ as a carrier for doxorubicin hydrochloride (DOX) loading and release (Fig. S22 $\dagger$ ). ${ }^{89}$ The assynthesised hollow mesoporous nanochains exhibited high 
drug loading and a good controlled release process due to their high specific surface area $\left(197.2 \mathrm{~m}^{2} \mathrm{~g}^{1}\right)$. The drug loading capacity of $\gamma-\mathrm{Fe}_{2} \mathrm{O}_{3} @ \mathrm{mSiO}_{2}$ was $167.5 \mathrm{l} \mathrm{g}$ per $\mathrm{mg}$ of carrier. Moreover, the drug release rate of DOX loaded onto the sample under natural conditions was very slow in the first $7 \mathrm{~h}$ and reached about $51 \%$ when extended to $80 \mathrm{~h}$ (Fig. S23 $\dagger$ ). ${ }^{89}$

The magnetite dual-targeting of methylene bis acryl amidemeta acrylic acid P(MBAAm-co-MAA) with folic acid (FA) linkage as a DOX carrier was studied by Yang et al (Fig. 11). The DOX loading capacity of the dual-targeting hollow P(MBAAm-coMAA) microspheres (as high as $176 \mathrm{mg}$ per $\mathrm{mg}$ of carrier) was measured, and about $61 \%$ encapsulation efficiency was reported in the case of an initial DOX concentration of $230 \mathrm{mg}$ $\mathrm{mL}^{-1}$. On the other hand, the release behavior of the dualtargeting hollow microspheres was dependent on the $\mathrm{pH}$ values in the environment. It was found that about $28 \%$ of loaded DOX was released from the carrier after $8 \mathrm{~h}$ in nearneutral conditions ( $\mathrm{pH} 7.4$ ). Finally, about $42 \%, 48 \%$ and $95 \%$ of the DXR drugs loaded onto the carrier were released at $\mathrm{pH}$ 6.0, 5.0 and 4.0 after $10 \mathrm{~h}$, respectively, which was noticeably faster than the release rate under neutral conditions (Fig. S24†). ${ }^{90}$

$\mathrm{Li}$ and co-workers synthesized and characterized hollow magnetic nanoparticles (HMNPs) and studied their drug delivery as a phase-change material (PCM). In this method, DXR as a model drug was loaded into the HMNPs carrier; about $4 \%$ of DXR was released from HMNP@PCM@DXR at physiological temperature, whereas around $80 \%$ of DXR was released in 30 min at $42{ }^{\circ} \mathrm{C}$. ${ }^{11}$

Zhou and co-workers studied multiple shell hollow $\mathrm{Fe}_{3} \mathrm{O}_{4}$ NPs assembled with lignin and grafted with folic acid as a nanocarrier for DXR delivery. ${ }^{92}$ The drug loading capacity of the as-prepared NPs was $67.5 \pm 6 \%$. The release behaviour of DXR from the drug-loaded NPs was considered in PBS buffer solutions at pH 5.5 and 7.4 over 8 h; only 19\% and 13.4\% of DXR leaked into the buffer solutions, respectively. In less than $30 \mathrm{~h}$, DXR was released smoothly from the drug-loaded NPs under

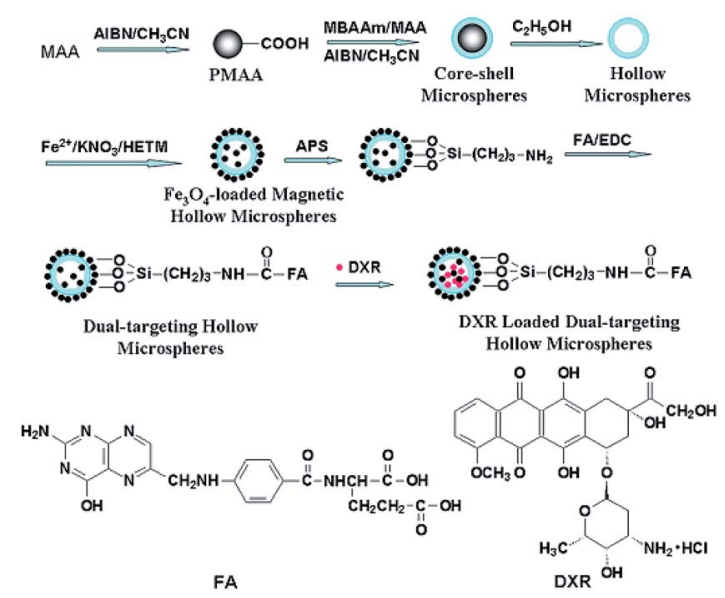

Fig. 11 Preparation of magnetite and tumor dual-targeting P(MBAAmCO-MAA) hollow microspheres as anticancer drug-carriers and the chemical structures of FA and DXR molecules. ${ }^{90}$ different $\mathrm{pH}$ conditions; this was attributed to the existence of magnetite NPs and folic acid. ${ }^{\mathbf{2}}$

3.4.2. Cisplatin. Cisplatin, cis-platinum or cis-diamminedichloroplatinum(II) (CDDP) is a platinum-based chemotherapy drug that is used to treat various types of cancers, ${ }^{93}$ including sarcomas, ${ }^{94}$ some carcinomas (small cell lung cancer and ovarian cancer), ${ }^{93}$ lymphomas and germ cell tumors. ${ }^{94}$ Cisplatin was the first member of its class, which now also includes carboplatin and oxaliplatin. Recently, Lei and coworkers studied the effects of carboxymethyl chitosan-coated $\mathrm{Fe}_{3} \mathrm{O}_{4} / \mathrm{SiO}_{2}$ hollow microspheres (HMS-CMCS) in CDDP delivery. The loading efficiencies of CDDP in the HMS and HMSCMCS spheres were $37.34 \%$ and $50.62 \%$ and the loading capacities of CDDP were 127 and $172 \mu \mathrm{g}$ per $\mathrm{g}$ of carrier, respectively. Then, the drug was released from the carriers in PBS at $37^{\circ} \mathrm{C}$; the release rates of CDDP from the HMS and HMSCMCS microspheres in $100 \mathrm{~h}$ were 70 and $90 \mathrm{wt} \%$, respectively. However, due to the strong chemical bonds between the high polymer material and the drugs in the HMS-CMCS carrier, the release rate was fast and was higher than that of HMS in the same medium (Fig. S25 †). ${ }^{95}$

In another report, Deng and co-workers synthesized hollow $\mathrm{Fe}_{3} \mathrm{O}_{4} / \mathrm{SiO}_{2} @$ @PE-poly(L,D-lactide) $\quad\left(\mathrm{Fe}_{3} \mathrm{O}_{4} / \mathrm{SiO}_{2} @ P E G-P L A\right)$ nanoparticles and studied their use in drug delivery (Fig. S26 $\dagger$ ). ${ }^{96}$ Hence, CDDP as a model drug was loaded into the hollow carrier $\mathrm{Fe}_{3} \mathrm{O}_{4} / \mathrm{SiO}_{2} @ P E G-P L A$. Additionally, the CDDP loading efficiencies in HMS and HMS@PEG-PLA were 50.62\% and $37.34 \%$, while the loading amounts of CDDP in HMS and HMS@PEG-PLA were 172 and $127 \mu \mathrm{g}$ per mg of carrier. Also, in vitro drug release studies were carried out under physiological conditions in PBS at $37{ }^{\circ} \mathrm{C}$. Meanwhile, high release rates were attained due to the presence of the drug near the surface of the particles. Generally, HMS@PEG-PLA presented a slower release than HMS in the medium because of the strong chemical bonds between the drugs and the high polymer material (Fig. S27 †). ${ }^{96}$

Cheng and co-workers synthesized porous hollow nanoparticles (PHNPs) and modified them with herceptin to study the loading and release of CDDP as an anticancer drug by a diffusion-controlled slow process (Fig. S28†). ${ }^{97}$ The CDDP loading efficiency of PHNPs was determined to be up to $25 \%$. Moreover, fast release of CDDP from PHNPs occurred in physiological buffer, with $t_{1 / 2}=4 \mathrm{~h}$. However, the fabricated PHNPs with open pores ( $\sim 2$ to $4 \mathrm{~nm}$ ) and stable porous shells in neutral or basic physiological conditions could successfully provide many more active sites to adsorb higher amounts of the CDDP drug. On the other hand, the CDDP-PHNPs could target breast cancer SK-BR-3 cells, with $\mathrm{IC}_{50}$ values reaching $2.9 \mu \mathrm{M}$, much lower than that of $6.8 \mu \mathrm{M}$ for free CDDP. ${ }^{97}$

3.4.3. Camptothecin. Camptothecin (CPT) is a cytotoxic quinolone alkaloid which inhibits the DNA enzyme topoisomerase I. It was discovered in 1966 by Wall and Wani during systematic screening of natural products for anticancer drugs which are used for cancer treatment in traditional Chinese medicine. ${ }^{98}$ Zhu and co-workers successfully designed and constructed monodisperse magnetic hollow spheres based on iron oxide. Then, they used the as-prepared spheres as a carrier 
in a controlled CPT delivery system for anticancer drug delivery and cancer treatment in vitro (Fig. 12).

Generally, the $\mathrm{Fe}_{3} \mathrm{O}_{4}$ hollow spheres were loaded with CPT drug via soaking them in DMSO for $24 \mathrm{~h}$; the capacity was 176 $\mu \mathrm{g}$. Then, CPT release from the $\mathrm{Fe}_{3} \mathrm{O}_{4}$ hollow spheres occurred in PBS at $\mathrm{pH} 7.4$ and in DMSO with different incubation periods. However, once CPT- $\mathrm{Fe}_{3} \mathrm{O}_{4}$ was dispersed in DMSO for $0.5 \mathrm{~h}$, most of the CPT was released and could be detected in the supernatant. Additionally, the negligible drug leakage of the sample in PBS has great significance in the minimization of side effects.

Importantly, almost no death occurred in cells in the $\mathrm{Fe}_{3} \mathrm{O}_{4}$ group, indicating its negligible toxicity in vitro. ${ }^{99}$ In another report, Sahu and co-workers synthesized a hollow magnetic mesoporous silica-based multimodal theranostic nanoagent as an efficient carrier for high loading and controlled release of CPT (Fig. S29†). ${ }^{100}$ According to their results, these multifunctional nanoparticles are not only extremely stable in aqueous buffer but also possess appreciably good cytotoxicity through the induction of apoptosis. The drug-loading capacity of the assynthesised nanomagnetic carrier was $17.5 \%$. Generally, this high CPT loading is a result of the high surface area of hollow mesoporous silica, which provides more interior spaces and conjugation sites. The drug release is higher at neutral $\mathrm{pH}$ and less acidic $\mathrm{pH}$ compared to other systems in which the drug is covalently attached to the carrier through ester linkages. At pH 5.3 , an immediate release of $25 \%$ was observed after $10 \mathrm{~h}$, which gradually increased to $83 \%$ after $80 \mathrm{~h}$. The nanomagnetic product can be used as a carrier for CPT without premature release of the drug in blood vessels, and it also shows a sustained release pattern over a prolonged period of time inside the lysosomal compartment (Fig. S30†). ${ }^{100}$

Hollow magnetic core mesoporous double-shell nanostructures (HMMNSs) were studied as a nanocarrier for DOC and CPT delivery by Wu and co-workers. Based on UV-Vis data, about $150 \mathrm{mg}$ of DOC or $140 \mathrm{mg}$ of CPT as drug agents were loaded into $1 \mathrm{~g}$ of the HMMNSs. Meanwhile, only $1.8 \%$ (DOC) and $2.0 \%$ (CPT) of the loaded drugs were released into PBS solution at $\mathrm{pH} 7.4$ for up to $72 \mathrm{h.}{ }^{101}$

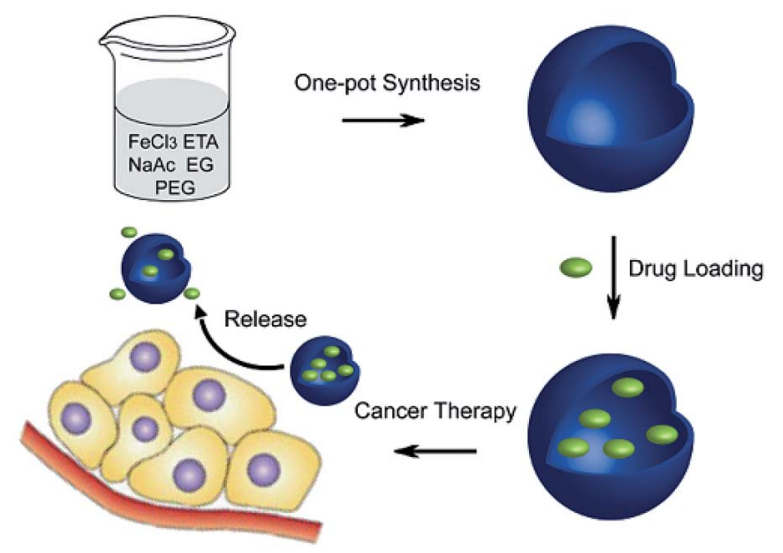

Fig. 12 Schematic of the one-pot synthesis of $\mathrm{Fe}_{3} \mathrm{O}_{4}$ hollow spheres and their application for chemotherapeutics. ${ }^{99}$
In another study, to investigate superparamagnetic hollow spheres as carriers for CPT delivery, $\mathrm{Fe}_{3} \mathrm{O}_{4}$ hollow spheres functionalized with (3-aminopropyl)triethoxysilane (APTES) with an average size of about $200 \mathrm{~nm}$ were prepared by Patil and co-workers. The drug storage capacity of the nanoparticles was $20 \mu \mathrm{g}$ of CPT per $\mathrm{mL}$ of carrier; also, about $30 \%$ of the CPT was released into PBS solution at $\mathrm{pH} 7.4$ during $4 \mathrm{~h}^{\mathrm{H}^{102}}$

3.4.4. Paclitaxel. Paclitaxel (PTXL) is known as a favourable anticancer therapeutic agent; it is used to treat a variety of breast, ovarian, and non-small cell lung cancers as well as head and neck carcinomas. ${ }^{103}$ Lou et al. employed a facile route to synthesize magnetic hollow porous nanocrystal shells (HPNSs) by Ostwald ripening as a hydrophobic drug delivery system. PTXL was selected as a carrier for controlled release, and the PTXL loading of the HPNSs was very high (20.2 wt\%). Moreover, the antitumor efficiency of the PTXL-HPNSs measured by 3-(4,5dimethylthiazol-2-yl)-2,5-diphenyltetrazolium bromide (MTT) assay was clearly improved compared with that of the free drug. Additionally, drug release of PTXL from the porous shell channels of the HPNSs was slow under $\mathrm{N}_{2}$ gas at $\mathrm{pH} 7.4$ within $24 \mathrm{~h}\left(1.5 \mathrm{mg} \mathrm{mL}^{-1}\right){ }^{104}$

3.4.5. Docetaxel. Docetaxel (TXL) is another anticancer drug that is used to treat a number of cancers. The drug loading capacity and release of TXL on the surface of magnetic mesoporous calcium nanocomposites (MMCNs) were considered by Lu et al. According to UV-Vis results, the MMCNs have a high drug loading capacity of TXL (about $0.153 \mathrm{~g}$ per $\mathrm{g}$ of carrier). The TXL loaded on MMCNs was normally released in pH 7.4 PBS buffer at $37{ }^{\circ} \mathrm{C}$. The TXL-MMCNs display anticancer ability; therefore, they are promising for applications in biomedical fields..$^{59}$

3.4.6. 5-Fluorouracil. 5-Fluorouracil (5-FU) is a hydrophilic drug molecule that exhibits significant inhibiting activity on tumor growth. ${ }^{105,106}$ The drug loading efficiency and release of 5FU on the surface of silanized hollow $\mathrm{Fe}_{3} \mathrm{O}_{4} /$ carbon/poly $(N$-isopropyl acrylamide) magnetic spheres (TSCHMSs) was considered by Chen et al. 5-FU was loaded onto the surface of TSCHMSs (30.3 $\mathrm{mg}$ of drug per $\mathrm{g}$ of carrier), and its release behavior was evaluated at $35{ }^{\circ} \mathrm{C}$ and $50{ }^{\circ} \mathrm{C}$ with applied magnetic field induction. At $35{ }^{\circ} \mathrm{C}, 18.8 \%$ of the drug was released from the TSCHMSs material. The drug release rate increased at $50{ }^{\circ} \mathrm{C}$, at which temperature $36.2 \%$ of 5 -FU was successfully released (Fig. S31 and S32†). ${ }^{107}$

\section{Conclusions}

In this review, we outline the recent advances in multifunctional HMNPs for adsorption and delivery of various natural and chemical pharmaceutical applications. HMNPs have the desired properties for safe use as pharmaceutical excipients. Hollow morphology, low density, large pore size, magnetic separation and high surface area are some advantages of these materials for drug delivery. These systems have great utility in controlled release and targeting of almost all classes of bioactive molecules, as discussed in this review. Despite the numerous challenges of these materials, HMNPs are indeed promising candidates for pharmaceutical and biological applications. 
At the end, SWOT analysis of hollow magnetic nanomaterials provides understanding of their synthesis methods and how these materials can be used to create smart drug delivery systems.

Generally, these materials can target specific locations in the body. The dosage of drug can be more readily adjusted compared with traditional magnetic target drug carriers. Moreover, they are among the most beneficial compounds due to their low density and non-toxicity, which can provide more opportunities for cancer therapy and provide a pathway toward the treatment of challenging diseases.

However, one of the major weakness of hollow magnetic nanoparticles for drug delivery applications is the synthesis of specific magnetic hollow particles by various approaches and the simultaneous controlling and tuning of the shapes and sizes of the final particles. In addition, the drug molecules cannot remain in circulating systems in the body.

\section{Conflicts of interest}

There are no conflicts to declare.

\section{List of abbreviations}

$\begin{array}{ll}\text { AMF } & \text { Alternating magnetic field } \\ \text { APTES } & \text { (3-Aminopropyl)triethoxysilane } \\ \text { CPT } & \text { Camptothecin } \\ \text { CDDP } & \text { Cisplatin } \\ \text { CM } & \text { Casein micelle } \\ \text { DL } & \text { Drug loading } \\ \text { DOX } & \text { Doxorubicin } \\ \text { DOX } & \text { Doxorubicin hydrochloride } \\ \text { ENR } & \text { Enrofloxacin } \\ \text { FA } & \text { Folic acid } \\ \text { FR } & \text { Folate receptor } \\ \text { 5-FU } & \text { 5-Fluorouracile } \\ \text { HAp } & \text { Hydroxy apatite } \\ \text { HMMNSs } & \text { Hollow magnetic mesoporous Nanostructures } \\ \text { HMMS } & \text { Hollow magnetic mesoporous shell } \\ \text { HMSPs } & \text { Hollow structure superparamagnetic particles } \\ \text { HMNPs } & \text { Hollow magnetic nanoparticles } \\ \text { HPNSs } & \text { Hollow porous nanocrystal shells } \\ \text { IBU } & \text { Ibuprofen } \\ \text { IONPs } & \text { Iron oxide nano particles } \\ \text { LCST } & \text { Lower critical solution temperature } \\ \text { MAA } & \text { Meta acrylic acid } \\ \text { MBAAm } & \text { Methylene bis acryl amide } \\ \text { MHMS } & \text { Magnetic hollow mesoporous silica } \\ \text { MHSNs } & \text { Magnetic hollow silica nanosphere } \\ \text { MMCNs } & \text { Magnetic mesoporous calcium nano composites } \\ \text { MNPs } & \text { Magnetic nano particles } \\ \text { MOF } & \text { Metal organic framework } \\ \text { MTT } & \text { Methyl thiazolyl tetrazolium } \\ \text { MZHM- } & \text { Magnetic ZnFe } O_{4} \text { hollow microsphere silica shells } \\ \text { MSs } & \\ \text { PBS } & \text { Phosphate buffer saline } \\ \text { PCM } & \text { Phase change material } \\ & \end{array}$

PEG Poly ethylene glycol

PHNPs Porous hollow nanoparticles

PLA Poly(L,D-lactide)

PTXL Paclitaxel

SBF Simulated body fluid

SCPs Solid carbon particles

SPIO Super paramagnetic iron oxide

TSCHMSs Silanized hollow $\mathrm{Fe}_{3} \mathrm{O}_{4} /$ carbon/poly( $N$-isopropyl acrylamide) magnetic spheres

TXL Docetaxel

UV-Vis Ultraviolet-visible

VAN Vancomycin

\section{Acknowledgements}

The authors gratefully acknowledge financial support from the Research Council of Alzahra University.

\section{Notes and references}

1 S. Kralj and D. Makovec, ACS Nano, 2015, 9, 9700-9707.

2 M. Tadic, S. Kralj, M. Jagodic, D. Hanzel and D. Makovec, Appl. Surf. Sci., 2014, 322, 255-264.

3 J. W. Bulte, Methods Mol. Med., 2006, 124, 419-439.

4 A. Amoozadeh, M. Malmir, N. Koukabi and S. Otokesh, J. Chem. Res., 2015, 39, 694-697.

5 A. Elhampour, M. Malmir, E. Kowsari, F. Boorboor ajdari and F. Nemati, RSC Adv., 2016, 6, 96623-96634.

6 V. F. Vavsari, G. M. Ziarani, S. Balalaie, M. Karimi, A. Latifi and A. Badiei, Synfacts, 2016, 12, 1215.

7 G. M. Ziarani, Z. Kazemi, P. Gholamzadeh, A. Badiei and M. Afshar, Appl. Organomet. Chem., 2017, 31, e3830-e3836.

8 G. M. Ziarani, P. Gholamzadeh, A. Badiei and V. F. Vavsari, Res. Chem. Intermed., 2018, 44, 277-288.

9 V. F. Vavsari, G. M. Ziarani, S. Balalaie, A. Badiei, F. Golmahammadi, S. Ramezanpour and F. Rominger, ChemistrySelect, 2017, 2, 3496-3499.

10 G. M. Ziarani, L. Seiedakbari, P. Gholamzadeh and A. Badiei, Iran. J. Catal., 2017, 7, 137-145.

11 S. Sadjadi, M. Malmir and M. M. Heravi, $R S C A d v$., 2017, 7, 36807-36818.

12 S. Sadjadi, M. M. Heravi and M. Malmir, J. Taiwan Inst. Chem. Eng., 2018, 86, 240-251.

13 K. Ulbrich, K. Holá, V. Šubr, A. Bakandritsos, J. Tuček and R. Zbořil, Chem. Rev., 2016, 116, 5338-5431.

14 N. F. Frey, S. Peng, K. Cheng and S. Sun, Chem. Soc. Rev., 2009, 38, 2532-2542.

15 Z. Sun and S. Sun, in Biomedical Nanotechnology: Methods and Protocols, Methods in Molecular Biology, ed. S. H. Petrosko and E. S. Day, Springer, 2017, vol. 1570, pp. 73-90.

16 L. P. Zhu, H. M. Xiao and S. Y. Fu, Cryst. Growth Des., 2007, 7, 177-182.

17 X. G. Wen, S. H. Wang, Y. Ding, Z. L. Wang and S. H. Yang, J. Phys. Chem. B, 2005, 109, 215-220.

18 B. Y. Geng, F. M. Zhan, H. Jiang, Y. J. Guo and Z. J. Xing, Chem. Commun., 2008, 5773-5775. 
19 W. Xie, Z. Guo, F. Gao, Q. Gao, D. Wang, B. Liaw, Q. Cai, X. Sun, X. Wang and L. Zhao, Theranostics, 2018, 8, 32843307.

20 K. E. Albinali, M. M. Zagho, Y. Deng and A. Elzatahry, Int. J. Nanomed., 2019, 14, 1707-1723.

21 X. W. Lou, L. A. Archer and Z. Yang, Adv. Mater., 2008, 20, 3987-4019.

22 H. J. Fan, U. Gösele and M. Zacharias, Small, 2007, 3, 16601671.

23 J. Y. Zhong, C. B. Cao, Y. Y. Liu, Y. N. Li and W. S. Khan, Chem. Commun., 2010, 46, 3869-3871.

24 Y. Wang, Q. S. Zhu and L. Tao, CrystEngComm, 2011, 13, 4652-4657.

25 W. Ostwald, Z. Phys. Chem., 1897, 22, 289-330.

26 W. Cheng, K. B. Tang, Y. X. Qi, J. Sheng and Z. P. Liu, J. Mater. Chem., 2010, 20, 1799-1805.

27 A. D. Smigelskas and E. O. Kirkendall, Trans. AIME, 1947, 171, 130-142.

28 B. Jia and L. Gao, J. Phys. Chem. C, 2008, 112, 666-671.

29 P. Hu, L. Yu, A. Zuo, C. Guo and F. Yuan, J. Phys. Chem. C, 2009, 113, 900-906.

30 S. W. Kim, M. Kim, W. Y. Lee and T. Hyeon, J. Am. Chem. Soc., 2002, 124, 7642-7643.

31 B. Tan and S. E. Rankin, Langmuir, 2005, 21, 8180-8187.

32 Y. Ding, Y. Hu, X. Jiang, L. Zhang and C. Yang, Angew. Chem., Int. Ed., 2004, 43, 6369-6372.

33 Q. He, Z. Wu and C. Huang, J. Nanosci. Nanotechnol., 2012, 12, 2943-2954.

34 S. E. Skarabalak, J. Chen, Y. Sun, X. Lu, L. Au and C. M. Cobley, Acc. Chem. Res., 2008, 41, 1587-1595.

35 V. F. Vavsari, G. M. Ziarani and A. Badiei, $R S C A d v ., 2015,5$, 91686-91707.

36 Z. Bahrami, A. Badiei and G. M. Ziarani, Int. J. Bio-Inorg. Hybrid Nanomater., 2015, 4, 121-128.

37 Z. Bahrami, A. Badiei and G. M. Ziarani, J. Nanopart. Res., 2015, 125, 1-12.

38 A. Badiei, I. Haririan, A. Jahangir and G. M. Ziarani, Dyn. Biochem. Process Biotechnol. Mol. Biol., 2009, 3, 48-50.

39 B. Karimi, F. Mansouri and H. M. Mirzaei, ChemCatChem, 2015, 7, 1736-1789.

40 S. Laurent, D. Forge, M. Port, A. Roch, C. Robic, L. V. Elst and R. N. Muller, Chem. Rev., 2008, 108, 2064-2210.

41 Y. Si, M. Chen and L. Wu, Chem. Soc. Rev., 2016, 45, 690714.

42 L. H. Reddy, J. L. Arias, J. Nicolas and P. Couvreur, Chem. Rev., 2012, 112, 5818-5878.

43 A. K. Guptaa and M. Gupta, Biomaterials, 2005, 26, 39954021.

44 D. B. Robinson, H. H. J. Persson, H. Zeng, G. Li, N. Pourmand, S. Sun and S. X. Wang, Langmuir, 2005, 21, 3096-3103.

45 S. W. Kim, S. Kim, J. B. Tracy, A. Jasanoff and M. G. Bawendi, J. Am. Chem. Soc., 2005, 127, 4556-4557.

46 F. M. Zehentbauer, C. Moretto, R. Stephen, T. Thevar, J. R. Gilchrist, D. Pokrajac, K. L. Richard and J. Kiefer, Spectrochim. Acta, Part A, 2014, 121, 147-151.

47 E. J. K. Al -Yasari, Med. J. Babylon, 2014, 11, 768-775.
$48 \mathrm{X}$. Chen, R. Klingeler, M. Kath, A. A. El Gendy, K. Cendrowski, R. J. Kalenczuk and E. Borowiak-Palen, ACS Appl. Mater. Interfaces, 2012, 4, 2303-2309.

49 Q. He, J. Liu, J. Liang, X. Liu, D. Tuo and W. Li, Materials, 2018, 11, 247-263.

50 B. Q. Lu, Y. J. Zhu, G. F. Cheng and Y. J. Ruan, Mater. Lett., 2013, 104, 53-56.

51 M. Sasidharan, H. N. Luitel, N. Gunawardhana, M. Inoue, S.-i. Yusa, T. Watari and K. Nakashima, Mater. Lett., 2012, 73, 4-7.

52 S. W. Cao, Y. J. Zhu, M. Y. Ma, L. Li and L. Zhang, J. Phys. Chem. C, 2008, 112, 1851-1856.

53 S. W. Cao and Y. J. Zhu, J. Phys. Chem. C, 2008, 112, 1214912156.

54 L. Y. Xia, M. Q. Zhang, C. Yuan and M. Z. Rong, J. Mater. Chem., 2011, 21, 9020-9026.

55 X. Zhu, S. Zhang, L. Zhang, H. Liu and J. Hu, RSC Adv., 2016, 6, 58511-58515.

56 W. Zhao, H. Chen, Y. Li, L. Li, M. Lang and J. Shi, Adv. Funct. Mater., 2008, 18, 2780-2788.

57 X. Zhao, P. Du and P. Liu, Mol. Pharmaceutics, 2012, 9, 33303339.

58 J. Zhou, W. Wu, D. Caruntu, M. H. Yu, A. Martin, J. F. Chen, C. J. O'Connor and W. L. Zhou, J. Phys. Chem. C, 2007, 111, 17473-17477.

59 B.-Q. Lu, Y.-J. Zhu, H.-Y. Ao, C. Qi and F. Chen, ACS Appl. Mater. Interfaces, 2012, 4, 6969-6974.

60 Y. Yang, X. Guo, K. Wei, L. Wang, D. Yang, L. Lai, M. Cheng and Q. Liu, J. Nanopart. Res., 2014, 16, 2210-2214.

61 C. Wang, J. Yan, Z. Li, H. Wang and X. Cui, J. Nanopart. Res., 2013, 15, 1937-1942.

62 D. Yang, K. Wei, Q. Liu, Y. Yang, X. Guo, H. Rong, M. L. Cheng and G. Wang, Mater. Sci. Eng., C, 2013, 33, 2879-2884.

63 L. Zhang, Y. Sun, W. Jia, S. Ma, B. Song, Y. Li, H. Jiu and J. Liu, Ceram. Int., 2014, 40, 8997-9002.

64 E. V. Hersh, S. Cooper, N. Betts, D. Wedell and K. MacAfee, Oral Surg., Oral Med., Oral Pathol., 1993, 76, 680-687.

65 J. M. Vargyas, J. D. Campeau and D. R. J. Mishell, Am. J. Obstet. Gynecol., 1987, 157, 944-950.

66 V. G. B. Alan, C. P. L. Isabel, M. M. Eugenia, G. R. Roberto, J. L. Coffer and M.-R. Miguel A, J. Nanomed. Res., 2016, 3, 15.

67 J. E. Dolfini, H. E. Applegate, G. Bach, H. Basch, J. Bernstein, J. Schwartz and F. L. Weisenborn, J. Med. Chem., 1971, 14, 117-119.

68 L. Li, H. Li, D. Chen, H. Liu, F. Tang, Y. Zhang, J. Ren and Y. Li, J. Nanosci. Nanotechnol., 2009, 9, 2540-2545.

69 L. Cui, A. Iwamoto, J. Q. Lian, H. Neoh, T. Maruyama, Y. Horikawa and K. Hiramatsu, Antimicrob. Agents Chemother., 2006, 50, 428-438.

70 K. Lin, L. Chen, P. Liu, Z. Zou, M. Zhang, Y. Shen, Y. Qiao, X. Liu and J. Chang, CrystEngComm, 2013, 15, 2999-3008.

71 F. Liu, J. Wang, Q. Cao, H. Deng, G. Shao, D. Y. B. Deng and W. Zhou, Chem. Commun., 2015, 51, 2357-2360.

72 R. T. Chlebowski, West. J. Med., 1979, 131, 364-368. 
73 P. G. Upton, K. T. Yamaguchi, S. Myers, T. P. Kidwell and R. J. Anderson, Cancer Treat Rep., 1986, 70, 503-507.

74 A. Kumar, B. Gautam, C. Dubey and P. K. Tripath, Int. J. Pharm. Sci. Rev. Res., 2014, 3, 4117-4128.

75 S. Xu, B. Yin, J. Guo and C. Wang, J. Mater. Chem. B, 2013, 1, 4079-4087.

76 X.-M. Zhu, J. Yuan, K. C.-F. Leung, S.-F. Lee, K. W. Y. Sham, C. H. K. Cheng, D. W. T. Au, G.-J. Teng, A. T. Ahuja and Y.-X. J. Wang, Nanoscale, 2012, 4, 5744-5754.

77 S.-J. Park, H.-S. Lim, Y. M. Lee and K. D. Suh, RSC Adv., 2015, 5, 10081-10088.

78 F. Lu, A. Popa, S. Zhou, J.-J. Zhu and A. C. S. Samia, Chem. Commun., 2013, 49, 11436-11438.

79 K. Cheng, Z. Sun, Y. Zhou, H. Zhong, X. Kong, P. Xia, Z. Guo and Q. Chen, Biomater. Sci., 2013, 1, 965-974.

80 Y.-M. Zhou, H.-B. Wang, M. Gong, Z.-Y. Sun, K.-C. Cheng, X.-k. Kong, Z. Guo and Q. W. Chen, Dalton Trans., 2013, 42, 9906-9913.

81 W. Ji, N. Li, D. Chen, Y. Jiao, Q. Xu and J. Lu, RSC Adv., 2014, 4, 51055-51061.

82 Y.-K. Peng, Y.-J. Tseng, C.-L. Liu, S.-W. Chou, Y.-W. Chen, S. C. Edman Tsang and P.-T. Chou, Nanoscale, 2015, 7, 2676-2687.

83 D. Li, J. Tang, J. Guo, S. Wang, D. Chaudhary and C. Wang, Chem.-Eur. J., 2012, 18, 16517-16524.

84 Y. Zhu, Y. Fang and S. Kaskel, J. Phys. Chem. C, 2010, 114, 16382-16388.

85 M. Karg and T. Hellweg, Curr. Opin. Colloid Interface Sci., 2009, 14, 438-450.

86 G. Liu, D. Hu, M. Chen, C. Wang and L. Wu, J. Colloid Interface Sci., 2013, 397, 73-79.

87 W.-H. Chiang, V. T. Ho, H.-H. Chen, W.-C. Huang, Y.-F. Huang, S.-C. Lin, C.-S. Chern and H.-C. Chiu, Langmuir, 2013, 29, 6434-6443.

88 L. Huang, L. Ao, W. Wang, D. Hu, Z. Sheng and W. Su, Chem. Commun., 2015, 51, 3923-3926.

89 W. Zhang, X. Si, B. Liu, G. Bian, Y. Qi, X. Yang and C. Li, J. Colloid Interface Sci., 2015, 456, 145-154.
90 X. Yang, L. Chen, B. Han, X. Yang and H. Duan, Polymer, 2010, 51, 2533-2539.

91 J. Li, Y. Hu, Y. Hou, X. Shen, G. Xu, L. Dai, J. Zhou, Y. Liu and K. Cai, Nanoscale, 2015, 7, 9004-9012.

92 Y. Zhou, Y. Han, G. Li, S. H. Yang, F. Xiong and F. Chu, Nanomaterials, 2019, 9, 188-201.

93 M. Rozencweig, D. D. von Hoff, M. Slavik and F. M. Muggia, Ann. Intern. Med., 1977, 86, 803-812.

94 L. H. Einhorn and S. D. Williams, N. Engl. J. Med., 1979, 300, 289-291.

95 M. Lei, T. Chao and Z. Lei, J. Nanopart. Res., 2014, 16, 24102416.

96 H. Deng and Z. Lei, Composites, Part B, 2013, 54, 194-199.

97 K. Cheng, S. Peng, C. Xu and S. Sun, J. Am. Chem. Soc., 2009, 131, 10637-10644.

98 M. E. Wall, M. C. Wani, C. E. Cook, K. H. Palmer, A. T. McPhail and G. A. Sim, J. Am. Chem. Soc., 1966, 88, 3888-3890.

99 Y. Zhu, J. Lei and Y. Tian, Dalton Trans., 2014, 43, 72757281.

100 S. Sahu, N. Sinha, S. K. Bhutia, M. Majhi and S. Mohapatra, J. Mater. Chem. B, 2014, 2, 3799-3808.

101 H. Wu, S. Zhang, J. Zhang, G. Liu, J. Shi, L. Zhang, X. Cui, M. Ruan, Q. He and W. Bu, Adv. Funct. Mater., 2011, 21, 1850-1862.

102 P. B. Patil, V. C. Karade, P. P. Waifalkar, S. C. Sahoo, P. Kollu, M. S. Nimbalkar, A. D. Chougale and P. S. Pati, IEEE Trans. Magn., 2017, 53, 5200604-5200607.

103 T. M. Mekhail and M. Markman, Expert Opin. Pharmacother., 2002, 3, 755-766.

104 B. Luo, S. Xu, W.-F. Ma, W.-R. Wang, S.-L. Wang, J. Guo, W.-L. Yang, J.-H. Hu and C.-C. Wang, J. Mater. Chem., 2010, 20, 7107-7113.

105 J. L. Grem, Invest. New Drugs, 2000, 18, 299-313.

106 T. Maria, A. Panagiotis and P. Ioannis, J. Cancer Ther., 2015, 6, 345-355.

107 L. Chen, H. Zhang, L. Li, Y. Yang, X. Liu and B. Xu, Appl. Polym. Sci., 2015, 132, 42617-42627. 